University of Nebraska - Lincoln

DigitalCommons@University of Nebraska - Lincoln

\title{
Mapping daily evapotranspiration at Landsat spatial scales during the BEAREX'08 field campaign
}

\author{
Martha C. Anderson \\ USDA-ARS, martha.anderson@ars.usda.gov \\ William P. Kustas \\ USDA-ARS \\ Joseph G. Alfieri \\ USDA-ARS, joe.alfieri@ars.usda.gov \\ Feng Gao \\ USDA-ARS, Feng.Gao@ars.usda.gov \\ Christopher R. Hain \\ University of Maryland - College Park, christopher.hain@nasa.gov
}

See next page for additional authors

Follow this and additional works at: https://digitalcommons.unl.edu/usdaarsfacpub

Anderson, Martha C.; Kustas, William P.; Alfieri, Joseph G.; Gao, Feng; Hain, Christopher R.; Prueger, John H.; Evett, Steven; Colaizzi, Paul D.; Howell, Terry A.; and Chávez, Jose L., "Mapping daily evapotranspiration at Landsat spatial scales during the BEAREX'08 field campaign" (2012). Publications from USDA-ARS / UNL Faculty. 1141.

https://digitalcommons.unl.edu/usdaarsfacpub/1141

This Article is brought to you for free and open access by the U.S. Department of Agriculture: Agricultural Research Service, Lincoln, Nebraska at DigitalCommons@University of Nebraska - Lincoln. It has been accepted for inclusion in Publications from USDA-ARS / UNL Faculty by an authorized administrator of DigitalCommons@University of Nebraska - Lincoln. 


\section{Authors}

Martha C. Anderson, William P. Kustas, Joseph G. Alfieri, Feng Gao, Christopher R. Hain, John H. Prueger, Steven Evett, Paul D. Colaizzi, Terry A. Howell, and Jose L. Chávez 


\title{
Mapping daily evapotranspiration at Landsat spatial scales during the BEAREX'08 field campaign
}

\author{
Martha C. Anderson a,*, William P. Kustas ${ }^{a}$, Joseph G. Alfieri ${ }^{a}$, Feng Gao ${ }^{\text {a }}$, Christopher Hain ${ }^{\text {b }}$, \\ John H. Prueger ${ }^{c}$, Steven Evett ${ }^{\mathrm{d}}$, Paul Colaizzi ${ }^{\mathrm{d}}$, Terry Howell ${ }^{\mathrm{d}}$, José L. Chávez ${ }^{\mathrm{e}}$ \\ ${ }^{\mathrm{a}}$ USDA-ARS, Hydrology and Remote Sensing Laboratory, Beltsville, MD, USA \\ ${ }^{\mathrm{b}}$ Earth System Science Interdisciplinary Center, University of Maryland, College Park, MD, USA \\ ${ }^{c}$ USDA-ARS National Laboratory for Agriculture and Environment, Ames, IA, USA \\ ${ }^{\mathrm{d}}$ USDA-ARS Conservation E Production Research Laboratory, Bushland, TX, USA \\ ${ }^{\mathrm{e}}$ Department of Civil and Environmental Engineering, Colorado State University, Fort Collins, CO, USA
}

\section{A R T I C L E I N F O}

Article history:

Available online 27 June 2012

\section{Keywords:}

Evapotranspiration

Remote sensing

Thermal

Land-surface temperature

\begin{abstract}
A B S T R A C T
Robust spatial information about environmental water use at field scales and daily to seasonal timesteps will benefit many applications in agriculture and water resource management. This information is particularly critical in arid climates where freshwater resources are limited or expensive, and groundwater supplies are being depleted at unsustainable rates to support irrigated agriculture as well as municipal and industrial uses. Gridded evapotranspiration (ET) information at field scales can be obtained periodically using land-surface temperature-based surface energy balance algorithms applied to moderate resolution satellite data from systems like Landsat, which collects thermal-band imagery every 16 days at a resolution of approximately $100 \mathrm{~m}$. The challenge is in finding methods for interpolating between ET snapshots developed at the time of a clear-sky Landsat overpass to provide complete daily time-series over a growing season. This study examines the efficacy of a simple gap-filling algorithm designed for applications in data-sparse regions, which does not require local ground measurements of weather or rainfall, or estimates of soil texture. The algorithm relies on general conservation of the ratio between actual ET and a reference ET, generated from satellite insolation data and standard meteorological fields from a mesoscale model. The algorithm was tested with ET retrievals from the Atmosphere-Land Exchange Inverse (ALEXI) surface energy balance model and associated DisALEXI flux disaggregation technique, which uses Landsat-scale thermal imagery to reduce regional ALEXI maps to a finer spatial resolution. Daily ET at the Landsat scale was compared with lysimeter and eddy covariance flux measurements collected during the Bushland Evapotranspiration and Agricultural Remote sensing EXperiment of 2008 (BEAREX08), conducted in an irrigated agricultural area in the Texas Panhandle under highly advective conditions. The simple gap-filling algorithm performed reasonably at most sites, reproducing observed cumulative ET to within 5-10\% over the growing period from emergence to peak biomass in both rainfed and irrigated fields.
\end{abstract}

Published by Elsevier Ltd.

\section{Introduction}

Many water resource management applications require spatial information about daily and seasonal evapotranspiration (ET) at pixel scales resolving individual agricultural fields or even finer management zones within fields. To support these data needs, satellite-derived ET maps at moderate resolution (defined here as $\sim 100 \mathrm{~m}$ pixel dimension) are being generated and used operationally, particularly in the western United States where freshwater resources are becoming increasing limited [1]. Applications include

* Corresponding author. Address: 10300 Baltimore Ave., Beltsville, MD 20705, USA. Tel.: +1 301504 6616; fax: +1 3015048931.

E-mail address: martha.anderson@ars.usda.gov (M.C. Anderson). irrigation scheduling; monitoring compliance with water rights; negotiating water rights transfers, sales or leases; predicting changes in regional water use due to land-use and/or climate changes; and studying the impacts of agriculture on surrounding ecosystems and streamflow [2-5]. Daily ET information about water use at the scale of usage is critical for improving water resource management, and for robustly estimating landscape-scale water loss to the atmosphere.

The Bushland Evapotranspiration and Agricultural Remote sensing EXperiment of 2008 (BEAREX08) [6] was conducted to gain a better understanding of evaporative water use in agricultural areas in the Southern High Plains, and in semi-arid irrigated landscapes in general. Intense groundwater withdrawals in this region from the High Plains Aquifer of the Ogallala system, primarily for 
irrigation, have caused a rapid and unsustainable decline in the water table level - in some places by more than $12 \mathrm{~m}$ over 17 years [7]. Studying evaporative processes in this region is also of interest from a micrometeorological standpoint. Irrigation of crops grown in arid and semi-arid climates can cause an "oasis effect", where horizontal advection of dry and warm air from adjacent unirrigated areas can result in large evaporative fluxes over irrigated fields - often well in excess of the available radiative energy [8-11]. This produces large negative sensible heat fluxes midday, where heat is extracted from the dry air layer to drive the evaporation. It is important to determine whether models of ET used in operational applications can reproduce these large latent heat fluxes.

In response to increasing demand for spatially distributed hydrologic information, many satellite-based approaches have been developed for routine monitoring of ET over large areas see [12] for a recent review. Land-surface temperature (LST) derived from thermal infrared (TIR) band imagery is a valuable diagnostic for estimating evaporative flux patterns, serving as a proxy indicator of the surface moisture status over a range in spatial scales $[13,14]$. While TIR data are available from an array of satellite sensors, at present the Landsat satellites are the only platforms that provide routine, global thermal imagery at scales that resolve water use patterns over heterogeneous agricultural areas - at $60-120-\mathrm{m}$ resolution for Landsats 7 and 5 , respectively [1]. The overpass frequency of Landsat (16 days for a single system), however, is not optimal for ET monitoring. Moisture conditions on the ground can be very dynamic, responding to rainfall and irrigation as well as heterogeneous drying due to variations in soils, vegetation, topography, and local climate. Robust methods are required for interpolating between infrequent satellite overpasses to fulfill the daily/seasonal information requirement for operational management activities.

While coarser-scale TIR imaging devices, such as the $1-\mathrm{km}$ resolution Moderate Resolution Imaging Spectroradiometer (MODIS), can provide LST data for ET mapping on a near-daily basis for relatively large fields $[15,16]$, these data are too coarse to resolve water use at the scale of individual users in most irrigation districts. At the BEAREX site, MODIS LST shows little response to crop ET dynamics observed on the ground, which are dominated by regular small-scale (sub-pixel) irrigation applications. In contrast, over this landscape the MODIS LST signal is typically dominated by thermal emission from the mostly rainfed background (Fig. 1). In this case, Landsat-scale TIR data are required to provide ET information relevant to individual management units.

In this paper, we evaluate a standard technique for generating daily Landsat-scale ET maps, based on conserving the ratio of actual to reference ET $\left(f_{R E T}\right)$ between imaging dates. Using daily maps of a reference ET metric, describing the time-evolution of maximum ET expected under well-watered conditions, and moderateresolution $f_{R E T}$ maps determined on Landsat dates, daily ET can

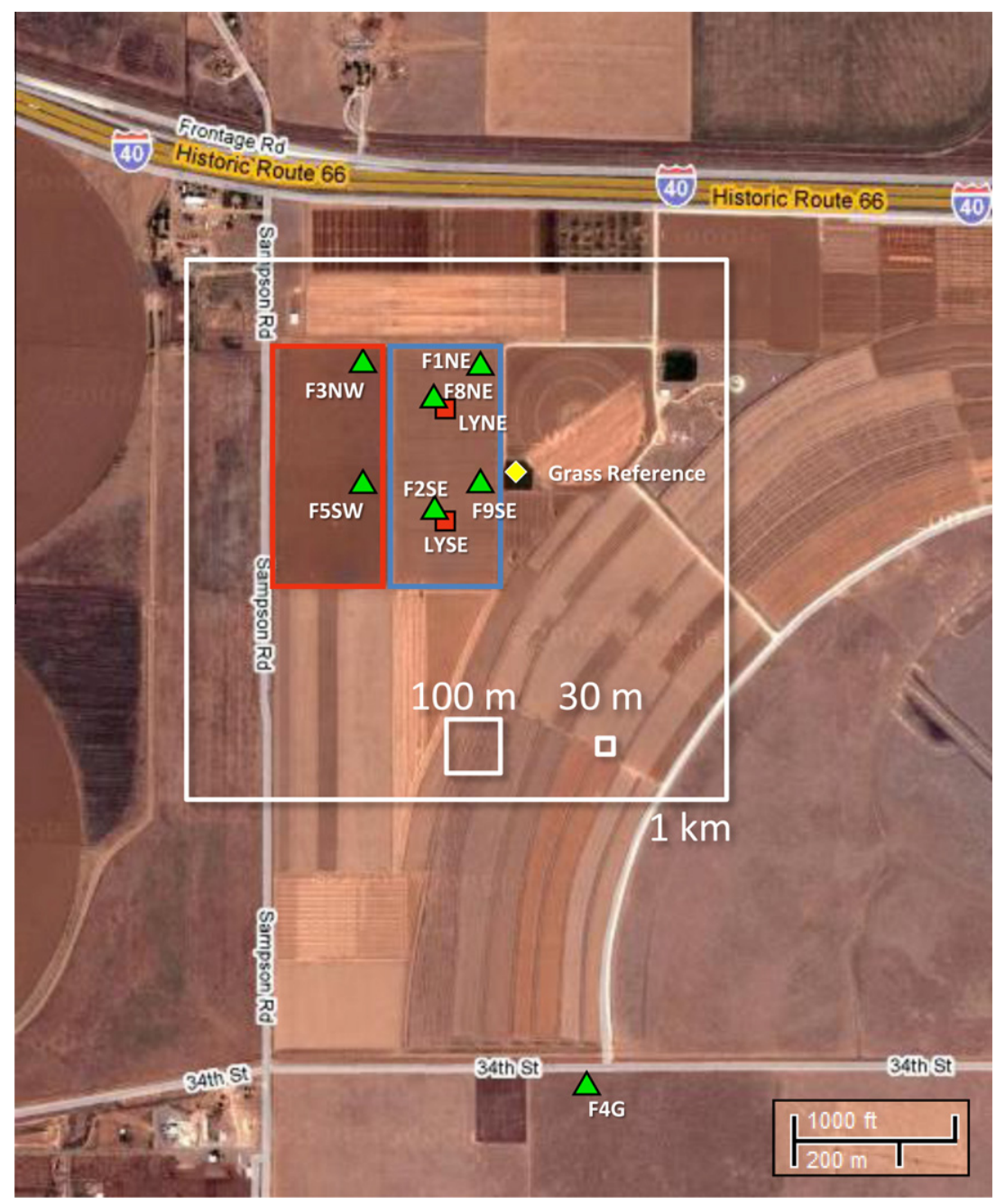

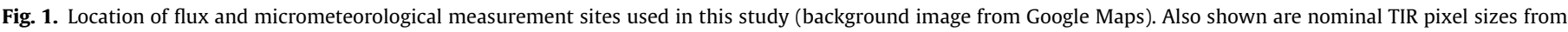
MODIS $(1 \mathrm{~km})$ and from raw $(\sim 100 \mathrm{~m})$ and sharpened $(30 \mathrm{~m})$ Landsat datasets. 
be estimated between imaging dates. Variations on this approach are used within the Surface Energy Balance for Land (SEBAL) [17], Mapping Evapotranspiration with Internalized Calibration (METRIC) [18], and other TIR energy balance models to upscale instantaneous ET snapshots to seasonal total water usage. METRIC, for example, uses ground-based measurements of reference ET acquired at a location within the imaging scene to drive the temporal interpolation [18]. In addition, local precipitation data are used in a soil water balance model to evolve the soil evaporation component of $f_{R E T}$ between Landsat dates, while the canopy component is spline interpolated in time. While this approach ties retrieved ET time series closely to local atmospheric conditions, improving the accuracy of the estimate in the vicinity of the station, it is more difficult to apply generally in areas where local weather station data are unavailable. Furthermore, the interpolation procedure requires accurate precipitation and soil texture data for the soil water balance computations, which can be difficult to obtain with adequate accuracy, especially in countries lacking dense in-situ monitoring networks.

Here we explore performance of an $f_{R E T}$ interpolation scheme designed for more general application, using only datasets that can be obtained remotely from satellite or modeled meteorological fields. Daily ET estimates generated with a Two-Source Energy Balance (TSEB) modeling approach [19] are evaluated in comparison with flux observations collected at multiple sites within the BEAREX08 study area over part of a growing season, from emergence to peak biomass. The TSEB is applied both locally, using micrometeorological tower-based measurements of LST and meteorological boundary conditions, and within a Landsat implementation using LST and air temperature boundaries derived from remote sensing and mesoscale analyses.

\section{Model description}

The energy balance model employed here is a multi-scale system designed to generate self-consistent flux assessments from field to regional/continental scales [20]. The regional Atmosphere-Land Exchange Inverse (ALEXI) model relates time-differential LST observations from geostationary satellites to the time-integrated energy balance within the surface-atmospheric boundary layer system. ALEXI has minimal reliance on absolute (instantaneous) air or surface temperature input data, and therefore provides a relatively robust flux determination at the coarse geostationary pixel scale. For finer scale ET applications, ALEXI flux fields can be spatially disaggregated using higher resolution LST information from polar orbiting systems (e.g., Landsat or MODIS) or from aircraft using an algorithm referred to as DisALEXI. Both ALEXI and DisALEXI use the TSEB land-surface representation to partition surface fluxes between the canopy and the soil. The ALEXI/DisALEXI/TSEB system is depicted schematically in Fig. 2 and described further below.

\subsection{Two-source energy balance model}

Surface energy balance models estimate ET by partitioning the energy available at the land surface $(R N-G$, where $R N$ is net radiation and $G$ is the soil heat flux, both in $\mathrm{W} \mathrm{m}^{-2}$ ) into turbulent fluxes of sensible and latent heating ( $H$ and $\lambda E$, respectively, in $\left.\mathrm{W} \mathrm{m}^{-2}\right)$ :

$R N-G=H+\lambda E$

where $\lambda$ is the latent heat of vaporization $\left(\mathrm{J} \mathrm{kg}^{-1}\right)$ and $E$ is ET $\left(\mathrm{kg} \mathrm{s}^{-1} \mathrm{~m}^{-2}\right.$ or $\left.\mathrm{mm} \mathrm{s}^{-1}\right)$. Surface temperature is a valuable metric for constraining $\lambda E$ because varying soil moisture conditions yield a distinctive thermal signature. Moisture deficiencies in the rootzone lead to vegetation stress and elevated canopy temperatures, while depleted water in the soil surface layer causes the soil component of the scene to heat rapidly. Typically LST is used to constrain the sensible heat flux estimate, while latent heat is computed as a residual in Eq. (1).

The two-source energy balance (TSEB) model of Norman et al. [19] (see also [21,22]) further breaks down total $\lambda E$ into estimates of soil evaporation and canopy transpiration. The TSEB partitions

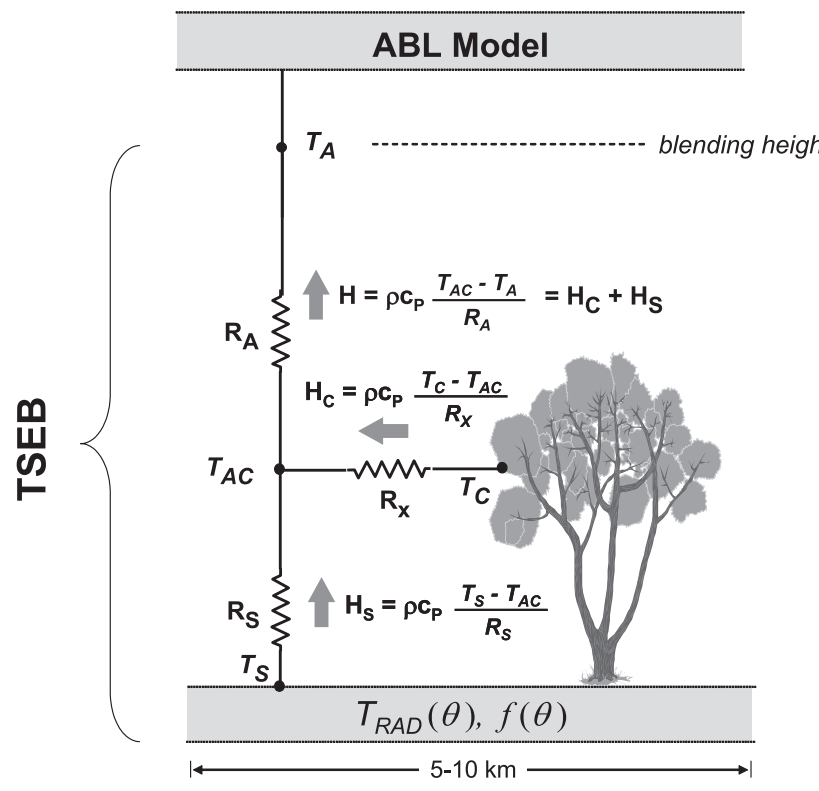

(a)
ALEXI

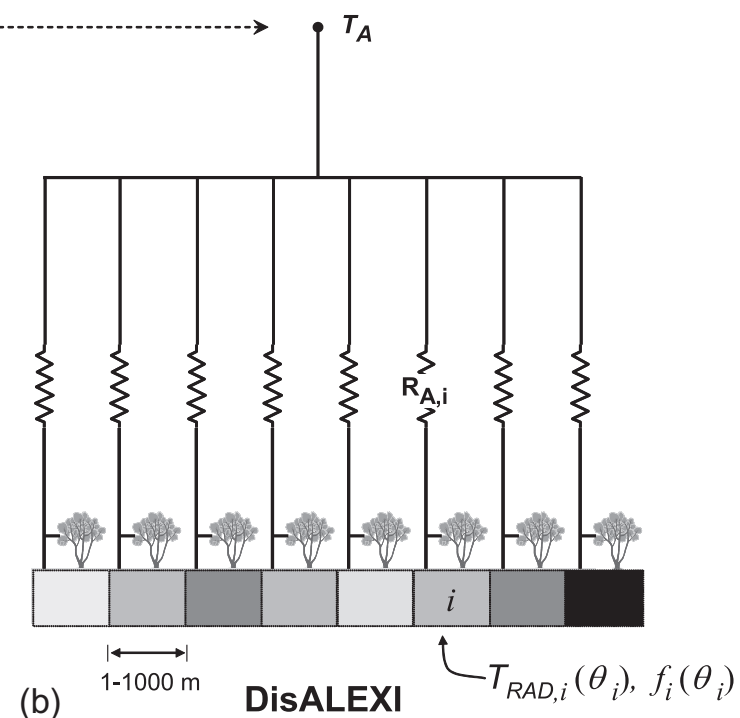

(b)

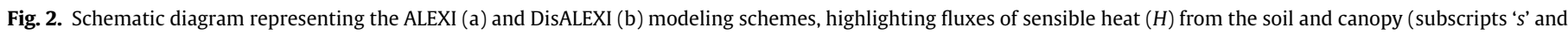

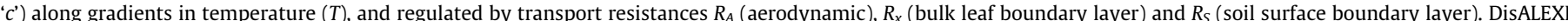

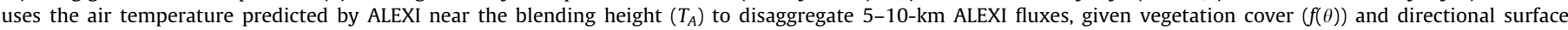
radiometric temperature $\left(T_{R A D}(\theta)\right)$ information derived from high-resolution remote-sensing imagery at look angle $\theta$. 
the composite surface radiometric temperature, $T_{R A D}$, obtained from thermal measurements into characteristic soil and canopy temperatures, $T_{S}$ and $T_{C}$, based on the local vegetation cover fraction apparent at the sensor view angle, $f(\theta)$ :

$T_{R A D}(\theta) \approx\left(f(\theta) T_{C}^{4}+[1-f(\theta)] T_{S}^{4}\right)^{1 / 4}$

(Fig. 2). For a canopy with a spherical leaf angle distribution and leaf area index (LAI), $f(\theta)$ can be approximated as

$f(\theta)=1-\exp \left(\frac{-0.5 \Omega(\theta) L A I}{\cos \theta}\right)$

where $\Omega(\theta)$ is a view angle dependent clumping factor, here assigned by vegetation class [23]. With information about $T_{R A D}$, LAI, and radiative forcing, the TSEB evaluates the soil (subscript "s") and the canopy (subscript "c") energy budgets separately, computing system and component fluxes of net radiation $\left(R N=R N_{C}+R N_{S}\right)$, sensible and latent heat $\left(H=H_{C}+H_{S}\right.$ and $\left.\lambda E=\lambda E_{C}+\lambda E_{S}\right)$, and soil heat conduction $(G)$. Because angular effects are incorporated into the decomposition of $T_{R A D}$, the TSEB can accommodate thermal data acquired at off-nadir viewing angles and can therefore be applied to both polar orbiting and geostationary satellite images.

The TSEB has a built-in mechanism for detecting thermal signatures of vegetation stress. In the original TSEB form, a modified Priestley-Taylor relationship (PT, [24]), applied to the divergence of net radiation within the canopy $\left(R N_{C}\right)$, provides an initial estimate of canopy transpiration $\left(\lambda E_{C}\right)$, while the soil evaporation rate $\left(\lambda E_{S}\right)$ is computed as a residual to the system energy budget. If the vegetation is stressed and transpiring at significantly less than the potential rate, the PT equation will overestimate $\lambda E_{C}$ and the residual $\lambda E_{S}$ will become negative. Condensation onto the soil is unlikely during midday on clear days, and therefore $\lambda E_{S}<0$ is considered a signature of system stress. Under such circumstances, the PT coefficient, $\alpha$, is iteratively reduced from its initial unstressed value (typically 1.26) until $\lambda E_{S} \sim 0$ (expected for dry conditions).

The PT approximation used as a starting point for estimating canopy transpiration in the original version of the TSEB does not account for advective effects, which can occur when the local surface is not in equilibrium with the overlying atmosphere. Advective (hot, dry, and windy) conditions were prevalent during BEAREX08, and therefore this dataset provides a means for testing whether the modified PT canopy transpiration approach used in the TSEB provides realistic system flux estimates. Agam et al. [25] found that the standard PT coefficient value of 1.26 yielded reasonable estimates of $\lambda E$ over a wide range of climate and vegetation cover conditions, with increased values of $\alpha$ required only above a vapor pressure deficit of $\sim 4 \mathrm{kPa}$. Colaizzi et al. [26] implemented and evaluated a transpiration formulation based on the Penman-Monteith (PM) equation [27] within the TSEB, accounting for advection. They found negligible difference in system ET (soil + canopy) estimate accuracy during the daytime hours in comparison with the PT method, as evaluated with respect to BEAREX08 datasets. However, the PM approach did yield more realistic partitioning between soil evaporation and canopy transpiration in that case.

\subsection{ALEXI}

Because the above-canopy air temperature boundary condition to the TSEB ( $T_{A}$ in Fig. 2 ) is difficult to specify accurately over large areas, application of the TSEB in a spatial mode, using satellite-derived LST imagery, must be performed with care. Small biases in $T_{A}$ with respect to $T_{R A D}$ can significantly corrupt model estimates of $H$, and therefore $\lambda E$ by residual - by up to $\sim 100 \mathrm{~W} \mathrm{~m}^{-2}$ per $^{\circ} \mathrm{C}$ depending on surface and meteorological conditions [28]. Significant biases in the measured surface-to-air temperature gradient should be expected due to both local land-atmosphere feedback not captured in the gridded $T_{A}$ field (typically generated either through mesoscale analysis or direct interpolation of synoptic weather station data), and to errors in atmospheric and emissivity corrections to $T_{R A D}$.

For regional-scale applications, the TSEB has been coupled in time-differencing mode with an atmospheric boundary layer (ABL) model to internally simulate land-atmosphere feedback on near-surface air temperature $\left(T_{A}\right)$, and to minimize impacts of errors in LST retrieval. In the ALEXI model, the TSEB is applied at two times $\left(t_{1}\right.$ and $\left.t_{2}\right)$ during the morning $A B L$ growth phase ( $\sim 1 \mathrm{~h}$ after sunrise and before local noon), using radiometric temperature data obtained from a geostationary platform typically at spatial resolutions of 3-10 km. ALEXI assumes a linear increase in $H$ between $t_{1}$ and $t_{2}$, and thus cloud-free conditions are required in the interim. Energy closure over this interval is provided by a simple slab model of ABL development [29], which relates the rise in air temperature in the mixed layer to the time-integrated influx of sensible heat from the land surface. As a result of this configuration, ALEXI uses only time-differential temperature signals, thereby minimizing flux errors due to absolute sensor calibration, as well as atmospheric and emissivity corrections [30]. The primary radiometric signal is the morning surface temperature rise, while the ABL model component uses only the general slope (lapse rate) of the atmospheric temperature profile [31], which is more reliably analyzed from synoptic radiosonde data than is the absolute temperature reference.

\subsection{DisALEXI}

For finer resolution assessments (smaller scales than can be provided by geostationary imagery), an ALEXI flux disaggregation scheme (DisALEXI) has been developed, with the combined system designed to generate consistent flux maps over a range in spatial scales - from continental coverage at 3-10 km resolution, to local area coverage at $1-100 \mathrm{~m}$ resolution [32]. The air temperature field, $T_{A}$, diagnosed by ALEXI at time $t_{2}$ serves as the upper boundary condition for a gridded implementation of the TSEB, which uses higher resolution LST and LAI data from polar orbiting systems like Landsat or the Moderate Resolution Imaging Spectroradiometer (MODIS) flying on-board NASA's Terra and Aqua satellites (Fig. 2). For Landsat disaggregation, $t_{2}$ in ALEXI can be set to the Landsat overpass time ( 10:30 local time), because it is typically within the linear morning portion of the diurnal $H$ curve. To ensure consistency between scales, compensating for potential biases between LST retrieval from the polar orbiting and geostationary sensors, in past applications either Landsat $T_{R A D}$ [33] or ALEXI $T_{A}$ [34] have been iteratively modified on the scale of an ALEXI pixel such that the average instantaneous $H$ flux at time $t_{2}$ from DisALEXI matches the coarser scale ALEXI flux (see Section 2.6).

\subsection{Upscaling instantaneous fluxes to daily totals}

ALEXI/DisALEXI fluxes were upscaled from instantaneous values retrieved at time $t_{2}$ (the Landsat imaging time) to daily total values by assuming that the evaporative fraction (EF):

$$
E F=1.1 \frac{\lambda E_{2}}{R N_{2}-G_{2}}
$$

is constant during the daylight hours, as described by Anderson et al. [35; see their Appendix C]. The coefficient 1.1 accounts for an observed underestimation of daily average $\mathrm{EF}$ by midday values by $5-10 \%$ [36-40]. With EF determined at time $t_{2}$, and hourly estimates of $R N$ and $G$ (described below), hourly latent and sensible heat fluxes at all times $t_{i}$ during the daylight hours were computed as 
$\lambda E_{i}=E F\left(R N_{i}-G_{i}\right)$

$H_{i}=R N_{i}-G_{i}-\lambda E_{i}$

Hourly net radiation for both ALEXI and DisALEXI is estimated using the analytical formalism for canopy radiative transfer described by Anderson et al. [41; see their Appendix B]. Using model-diagnosed soil and canopy component temperatures ( $T_{S}$ and $T_{C}$; Eq. (2)), along with LAI data and parameters describing leaf absorptivity in the visible, near infrared (NIR) and TIR wavebands, and soil reflectivity in the visible and NIR bands, the canopy model computes $R N_{S}, R N_{C}$ and $R N$ in a physically based yet computationally efficient way.

In this study, downwelling shortwave (SWDN) components of hourly $R N_{i}$ for both ALEXI and DisALEXI were provided by hourly GOES-based insolation data [42], while longwave atmospheric radiation (LWDN) can be estimated using GOES [43] or as an empirical function of standard meteorological data [44]. Upwelling shortwave radiation (SWUP) was computed by the canopy radiative transfer model, with soil reflectivity values tied to the MODIS albedo product (see below) and leaf absorptivities assigned by land-cover class [35]. Upwelling longwave (LWUP) radiation from the soil and canopy layers depends on $T_{S}$ and $T_{C}$, and on specified soil and leaf emissivities.

Because DisALEXI provides $T_{S}$ and $T_{C}$ at time $t_{2}$ (Landsat overpass) only, a simple technique was employed to provide the upwelling longwave model with hourly temperature component values, linking to departures from hourly air temperature input data $\left(T_{A i}\right)$. At time $t_{2}$ we compute

$$
\begin{aligned}
& d T_{c 2}=T_{c 2}-T_{A 2} \\
& d T_{s 2}=T_{s 2}-T_{A 2}
\end{aligned}
$$

Then two second order polynomial equations are fit describing the hourly departure $d T_{C i}\left(d T_{S i}\right)$. These polynomials were formulated to yield values of $d T_{C 2}\left(d T_{S 2}\right)$ at time $t_{2}$, and values of 0 at sunrise and sunset - i.e., $T_{S}$ and $T_{C}$ are nudged toward $T_{A}$ as the sensible heat flux approaches 0 . Comparisons of modeled upwelling longwave time series with 4-component net radiometer observations are shown in Section 4, below.

Finally, $G_{i}$ was modeled as a diurnally varying fraction of $R N_{S i}$ [45]. Hourly $\lambda E_{i}$ and $H_{i}$ values were computed using Eq. (5), and all fluxes were integrated over the daylight hours and expressed in units of $\mathrm{MJ} \mathrm{m}^{-2} \mathrm{~d}^{-1}$. Nighttime fluxes have been excluded from the current analysis, but will be addressed in future work using the techniques of Colaizzi et al. [26].

\subsection{Gap-filling}

To fill gaps in the retrieved daily flux time series - between Landsat overpass dates (DisALEXI), or during cloudy intervals (ALEXI) - we tested a simple approach conserving the ratio of actual ET to a reference ET $\left(f_{R E T}\right)$. The method used here is a simplification of the ALEXI gap-filling algorithm described by Anderson et al. [35], which conserved $f_{R E T}$ separately for the canopy and soil components of the system, tied to depleting pools of available water in the rootzone and soil surface layers of the soil profile. While that method performed well in tests in the US, it relies on the availability of accurate soil texture data that are not available globally. The gap-filling approach applied in the METRIC model [18] requires both soil texture and precipitation data, further limiting application in data sparse regions.

On days when a daytime ET retrieval is available at a given pixel in the ALEXI or DisALEXI model domains, $f_{R E T}$ is computed as

$f_{\text {RET }}=\mathrm{EDAY} / \mathrm{ERDAY}$

where EDAY is the actual ET model estimate and ERDAY is a measure of daytime reference ET, which can be obtained on a daily basis using GOES and meteorological data. On all intervening days $(d)$ between retrievals, Eq. (7) is inverted to compute daily actual ET, $\mathrm{EDAY}_{\mathrm{d}}$, as

$\mathrm{EDAY}_{d}=f_{\text {RETd }} * \mathrm{ERDAY}_{d}$

where ERDAY ${ }_{\mathrm{d}}$ is the reference ET for day $d$, and $f_{\text {RETd }}$ are daily values interpolated between $f_{R E T}$ values from bracketing retrievals. For DisALEXI, a spline interpolation function was employed between Landsat overpass dates. For ALEXI we have a significantly denser time series of $f_{R E T}$ derived from the geostationary imagery, with missing daily data due only to clouds rather than imaging interval. The average gap size in ALEXI coverage is 3.6 days over the US, reducing to 2.7 days over the Texas Panhandle due to less frequent cloud cover. We can therefore use this time-series information to filter for undetected clouds, which can corrupt the temperature rise signal used in ALEXI and add noise to flux estimates. Here we used a Savitsky-Golay [46] filter with a second order smoothing polynomial. The $f_{\text {RETd }}$ time series at each pixel were replaced with filtered and gap-filled values, and temporally smoothed daily ET fields (EDAYs) were computed using Eq. (8). While this may filter out some high frequency soil moisture signal in addition to cloud artifacts, the net effect was positive in supplying more temporally representative boundary conditions to DisALEXI.

Two sources of ERDAY ${ }_{d}$ data were tested: a local datastream, applying the Food and Agriculture Organization (FAO) PenmanMonteith formulation for reference ET [47] using local observations collected over a grass reference site; and a datastream based only on remote inputs, using the Penman-Monteith equation with meteorological inputs used in ALEXI (derived from mesoscale analyses of synoptic data) and insolation data from GOES.

\subsection{DisALEXI normalization}

To accommodate disaggregation with TIR data collected at arbitrary times around local noon (and into the afternoon, as with MODIS on Aqua), we evaluated the efficacy of using daytime total $H$ from ALEXI as the normalization basis rather than an instantaneous flux at some specific time. To take advantage of the smoothing applied to ALEXI EDAY ${ }_{\mathrm{s}}$ described above, a smoothed daytime $H$ ALEXI field (HDAYS) was computed as

$\mathrm{HDAY}_{s}=\mathrm{RNDAY}-\mathrm{GDAY}-\mathrm{EDAY}_{s}$

where RNDAY and GDAY are daytime-integrated net radiation and soil heat flux, respectively. In DisALEXI, $T_{A}$ for all Landsat pixels within a given ALEXI pixel was iteratively adjusted until the daytime $H$ from DisALEXI, averaged over the ALEXI pixel area, matched ALEXI HDAY $_{\mathrm{s}}$ at that pixel. This $H$ normalization results in adjustments to DisALEXI $\lambda E$ via energy balance, such that latent heat fields are also consistent between ALEXI and DisALEXI at the coarse ALEXI pixel scale.

Table 1

Locations of flux measurement sites used in this study.

\begin{tabular}{lllll}
\hline Site & Type & UTME $^{a}$ & UTMN $^{a}$ & Irrigated \\
\hline F1NE & EC & 218176 & 3898371 & Yes \\
F2SE & EC & 218173 & 3898143 & Yes \\
F3NW & EC & 217963 & 3898384 & No \\
F4G & EC & 218394 & 3896989 & No \\
F5SW & EC & 217950 & 3898162 & No \\
F8NE & EC & 218130 & 3898312 & Yes \\
F9SE & EC & 218122 & 3898093 & Yes \\
LYNE & Lysimeter & 218141 & 3898309 & Yes \\
LYSE & Lysimeter & 218133 & 3898081 & Yes
\end{tabular}

a UTM Zone 14S Easting (UTME) and Northing (UTMN) coordinates (in m). 


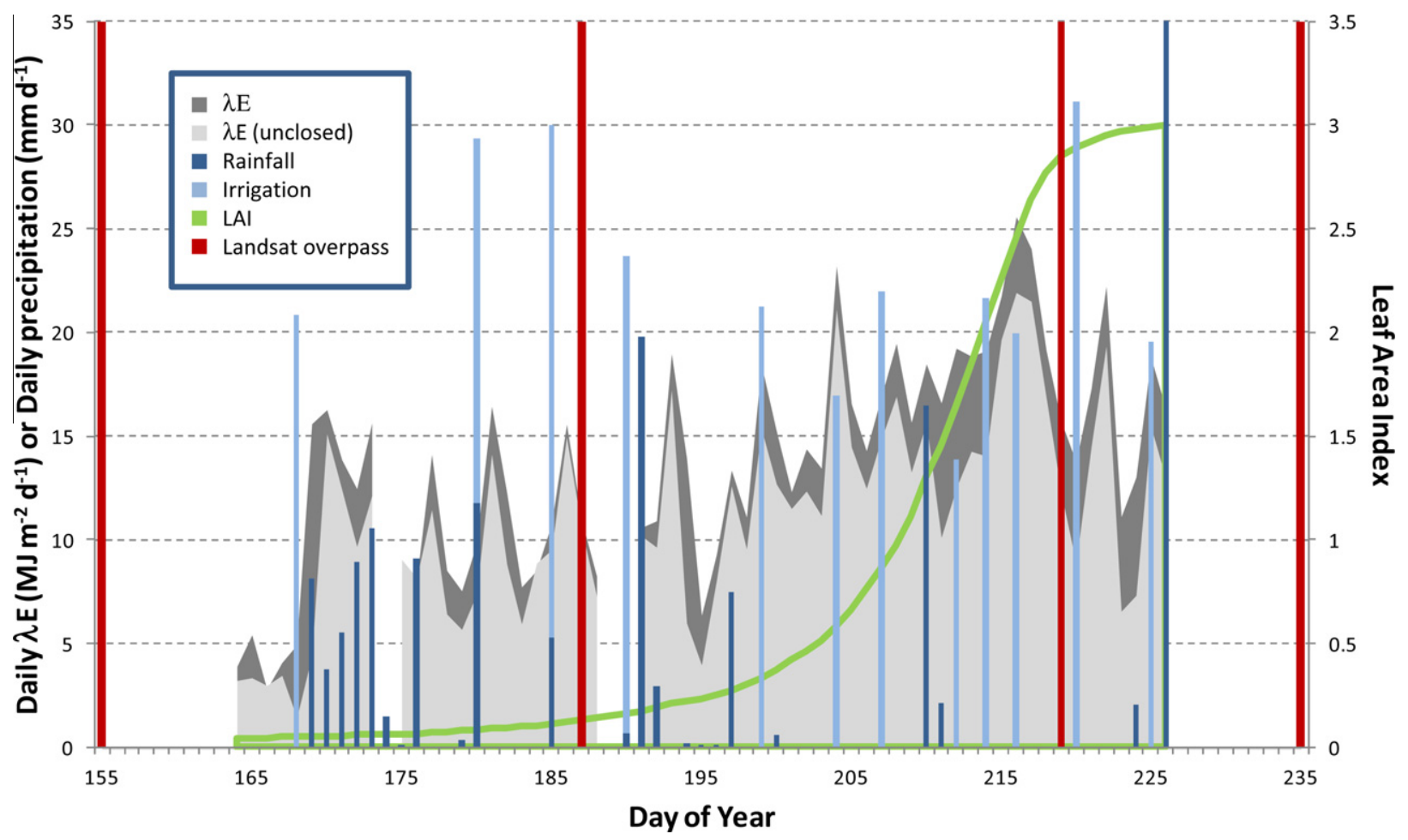

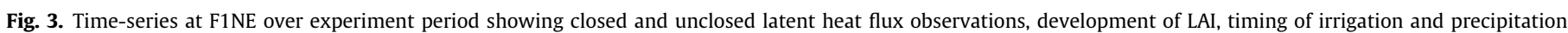
events, and timing of Landsat overpasses.

\section{Data}

\subsection{Site description}

The BEAREX08 experiment was conducted from June-August in 2008 at the USDA-ARS Conservation \& Production Research Laboratory (CPRL) in Bushland, Texas to study evaporative processes and land-atmosphere interactions in semi-arid, advective environments. The 10-km ALEXI pixel over CPRL includes agricultural fields (both irrigated and rainfed), natural vegetation, a concentrated animal feeding operation (CAFO), and residential/urban land-use. Details regarding site and instrumentation specifics are provided by Evett et al. [6].

Flux data collection was focused around paired irrigated/unirrigated cotton fields, each segmented into two areas: NE and SE (irrigated), and NW and SW (unirrigated). An unirrigated rangeland grass site provided a comparison of ET behavior over natural vegetation. In addition, a well-watered grass reference site was maintained nearby for in-situ reference ET data collection. Sites of flux data collection used in this study are indicated in Fig. 1 and listed in Table 1.

The study period covered phenological stages from emergence to close to peak biomass in the irrigated cotton field, from Day of Year (DOY) 164-226. Fig. 3 shows the time sequence of precipitation and irrigation events in the eastern irrigated field, along with the evolution in LAI and latent heat fluxes measured at the F1NE flux tower site. Irrigation was applied to the east field approximately every 5-9 days during this period. Occasionally, irrigation was also applied to west field to keep the crops alive.

\subsection{Flux and micrometeorological datasets}

\subsubsection{Lysimeter data}

The cotton fields were instrumented with monolithic weighing lysimeters $(3.0 \times 3.0 \mathrm{~m}$ horizontal dimension, and $2.4 \mathrm{~m}$ deep $)$, sampling the north and south segments of each field [6]. Crop growth on the unirrigated (west) field was very patchy, and conditions over the lysimeter were not representative of the surrounding $30 \mathrm{~m}$ area (pixel size of the ET grid). The NW and SW lysimeter data were therefore not used in this study.

Lysimeter ET measurements were quality controlled and aggregated to hourly timesteps, as described by Evett et al. [6]. Ancillary measurements of net radiation (and upwelling and downwelling shortwave/longwave components, acquired with Kipp and Zonen ${ }^{1}$ CNR-1 4-component net radiometers), solar radiation, soil heat flux, and standard meteorological data were collected in the vicinity of each lysimeter. Sensible heat flux is not measured directly by lysimetry, so $H$ was computed by residual as $R N-G-\lambda E$.

\subsubsection{Eddy covariance data}

This study also used eddy covariance (EC) flux data collected at 2 sites per field in the NE and SE fields, and 1 site per field in the NW and SW fields. The EC systems sample a larger footprint on the ground $(\sim 100 \mathrm{~m})$ than do the lysimeters, and therefore should be more representative of the $30-\mathrm{m}$ ET grid scale. Therefore EC data from the unirrigated west field were included in the comparisons, to provide contrast with the measurements over irrigated cotton. Data from the rainfed rangeland grass site (F4G) were also used. Instrumentation at these sites is described by Evett et al. [6] and Alfieri et al. [48].

Ancillary meteorological data, net radiation (four components), soil heat, and sensible and latent heat flux data collected at these tower sites were aggregated to hourly timesteps. EC data are subject to energy budget closure errors, such that often $R N-G>\lambda E+H$ $[49,50]$. To improve consistency with the model, which enforces closure through Eq. (1), a correction has been applied assigning

\footnotetext{
${ }^{1}$ Mention of trade names or commercial products in this report is solely for the purpose of providing specific information and does not imply recommendation or endorsement by the US Department of Agriculture.
} 
the residual error to the latent heat flux [51]. Closure was around $85 \%$ on average, but reduced to $75 \%$ during highly advective periods (DOY 212-217; see Fig. 3). Uncertainties in observed fluxes are correspondingly higher during these periods, with the true value likely bracketed between closed and unclosed flux measurements [52].

\subsubsection{Grass reference site}

To provide meteorological and radiation data for computing reference ET, a grass reference site was maintained just east of the irrigated cotton field (Fig. 1), with instrumentation described by Evett et al. [6]. Data used in reference ET computations include air temperature, relative humidity, wind speed, atmospheric pressure, net radiation, and soil heat flux.

\subsection{Biophysical data}

Biophysical measurements were obtained at several sites within the BEAREX08 study area during the course of the experiment. LAI was measured with a LI-COR leaf area meter (model LI-3100, Lincoln, Nebraska), and canopy height and fractional coverage data were also collected routinely. Alfieri et al. [48] correlated in situ LAI and canopy height observations with Normalized Difference Vegetation Index (NDVI) data extracted from high resolution airborne imagery acquired during BEAREX08, and developed daily time series at each of the flux sites.

\subsection{Satellite and mesoscale data}

Model implementation used thermal satellite data from both GOES and Landsat, along with vegetation/surface products from MODIS. To avoid gaps in imagery due to the scan-line corrector failure on Landsat 7, and to test performance with a single Landsat (upcoming scenario in the Landsat Data Continuity Mission era), only Landsat 5 (L5) scenes were used. Four predominantly clear scenes were processed from dates bracketing the period of flux collection: on DOY 155, 187, 219, and 235 (Fig. 3). The resulting dataset provides direct ET retrievals at a 16-32-day revisit interval.

Primary remote sensing inputs to ALEXI/DisALEXI include insolation, LST, LAI, and albedo. Meteorological inputs were obtained from mesoscale simulations, as described below.

\subsubsection{Insolation}

Insolation inputs for both ALEXI and DisALEXI were obtained from hourly GOES-based products at 20-km resolution [42,43]. Otkin et al. [53] compared GOES insolation estimates to pyranometer data from 11 sites in the United States Climate Reference Network (USCRN) over a continuous 15-month period. Average errors of $19 \%$ and $10 \%$ were obtained for predictions at hourly and daily timesteps, respectively (including both clear and cloudy-sky conditions).

\subsubsection{Land-surface temperature}

Brightness temperature data used over the continental US domain in ALEXI were obtained with the GOES-10 (western US) and -12 (east) Sounder instruments within the 10.2-11.2 $\mu$ m (Band 4) window, aggregated to a $10-\mathrm{km}$ resolution grid. Directional brightness temperature was atmospherically corrected and converted to radiometric temperature values using a technique described by French et al. [54] and estimates of directional surface emissivity computed as a function of nominal soil and leaf emissivities and LAI.

For DisALEXI, LST was retrieved from Band 6 on L5 following procedures outlined by Li et al. [55]. At-sensor brightness temperatures were atmospherically corrected using MODTRAN [56], corrected for emissivity, and then sharpened to the $30-\mathrm{m}$ resolution of the Landsat shortwave sensors using the NDVI-based procedure described by Anderson et al. [33].

\subsubsection{Leaf area index}

LAI fields used in both ALEXI and DisALEXI were tied to the MODIS 1-km 8-day composite LAI product (MOD15A, Collection 5) [57]. For ALEXI, the MODIS LAI products were aggregated to the $10-\mathrm{km}$ ALEXI grid, then bi-linearly interpolated in time to provide daily input fields.

In this implementation DisALEXI required LAI information at the $30-\mathrm{m}$ grid scale, and it is beneficial for the disaggregation that this field be as consistent as possible with the inputs to ALEXI. Therefore, a regression tree approach was applied, correlating Landsat reflectances with the MODIS LAI product [58]. Landsat 30-m reflectance data were calibrated and atmospherically corrected to surface reflectance using the Landsat Ecosystem Disturbance Adaptive Processing System (LEDAPS) [59]; then aggregated to MODIS resolution. A set of reference values were selected from the MODIS LAI product, limiting to pixels with high quality LAI values (i.e., the main radiative transfer algorithm was applied) and low sub-pixel variability in Landsat reflectance (i.e., focusing on relatively "pure" pixels). A relation table between the aggregated Landsat surface reflectances and high quality MODIS LAI was built at the MODIS spatial resolution. This relation table included data extracted from all of the imaging dates, and thus allowed coverage of a large dynamic range of LAI values. A regression tree approach (Cubist by RuleQuest) was used to train on samples (at the $1-\mathrm{km}$ MODIS resolution), and the regression trees were then applied to the Landsat surface reflectances to create Landsat LAI maps at 30-m resolution. Because MODIS high quality LAI values are used as references, the resulting Landsat LAI values are consistent with the MODIS LAI product. However, in some complex heterogeneous areas, the MODIS LAI product missed (or smoothed out) high LAI values in small agriculture fields. In order to incorporate these high LAI values in the training process, direct observations of LAI at the BEAREX sites were also included. The combination of LAI samples from the MODIS LAI product and field measurements provided a robust solution for computing LAI at Landsat 30-m resolution for this study. In lieu of ground observations of LAI, retrievals from a canopy reflectance inversion model, (e.g., [60]) applied to Landsat reflectance data can be used to provide training data at high LAI.

\subsubsection{Albedo}

Given the two-source nature of the TSEB model, albedo products representing bulk (soil + vegetation) surface properties cannot be directly used in ALEXI/DisALEXI, but rather were used to calibrate soil reflectance inputs to the canopy radiative transfer submodel. In ALEXI, the 1-km MODIS 16-day global albedo product (MCD43B3) was aggregated to the 10-km ALEXI grid and bi-linearly interpolated in time. Leaf absorptivities were held fixed at values tied to land-cover class [35], while soil background reflectances in the red and NIR bands at each pixel were iterated over a reasonable range of values until the model system (soil + canopy) reflectance converged on the MODIS albedo.

DisALEXI applications to Landsat used representative soil reflectance values derived from this ALEXI-MODIS iterative process, extracted from sparsely vegetated areas in the vicinity of CPRL. For both ALEXI and DisALEXI, LAI is an important input to the canopy model for weighting soil and leaf reflectance contributions to the modeled bulk surface albedo.

\subsubsection{Mesoscale data}

Meteorological inputs to ALEXI/DisALEXI and to the remote reference ET computation were obtained from analyses generated with the Fifth-Generation Pennsylvania State University/ National 

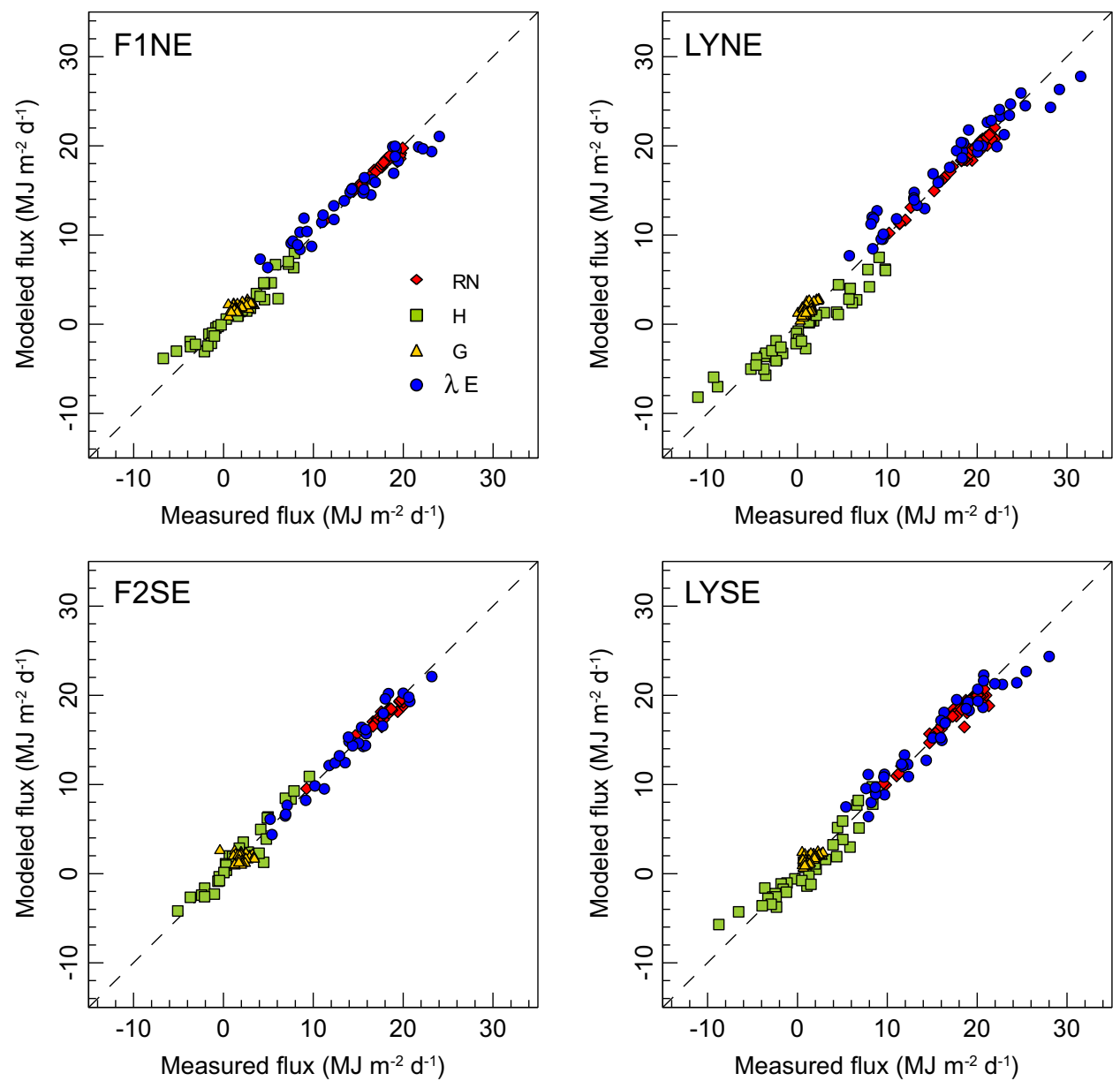

Fig. 4. Comparison of measured flux components at four flux sites with local TSEB model results, both integrated to daytime totals (MJ $\mathrm{m}^{-2} \mathrm{~d}^{-1}$ ).

Table 2

Quantitative measures of TSEB model performance ${ }^{\mathrm{a}}$ at daily timesteps for four flux sites.

\begin{tabular}{|c|c|c|c|c|c|c|c|c|}
\hline Flux & $N$ & $\bar{O}\left(\mathrm{MJ} \mathrm{m}^{-2} \mathrm{~d}^{-1}\right)$ & $\operatorname{MBE}\left(\mathrm{MJ} \mathrm{m}^{-2} \mathrm{~d}^{-1}\right)$ & $\operatorname{RMSD}\left(\mathrm{MJ} \mathrm{m}^{-2} \mathrm{~d}^{-1}\right)$ & $\operatorname{MAD}\left(\mathrm{MJ} \mathrm{m}^{-2} \mathrm{~d}^{-1}\right)$ & $r^{2}$ & $E$ & \% Error \\
\hline \multicolumn{9}{|l|}{ F1NE } \\
\hline$R N$ & 34 & 17.5 & 0.1 & 0.4 & 0.3 & 0.957 & 0.946 & 1.9 \\
\hline$\lambda E$ & 34 & 14.2 & 0.1 & 1.6 & 1.3 & 0.941 & 0.911 & 9.1 \\
\hline$H$ & 34 & 1.4 & 1.4 & 1.1 & 0.8 & 0.927 & 0.913 & 57.5 \\
\hline G & 34 & 1.9 & 1.9 & 0.7 & 0.5 & 0.345 & 0.294 & 28.5 \\
\hline All & 136 & 8.8 & 8.8 & 1.0 & 0.8 & 0.983 & 0.983 & 8.5 \\
\hline \multicolumn{9}{|l|}{$F 2 S E$} \\
\hline$R N$ & 32 & 18.1 & -0.2 & 0.5 & 0.4 & 0.949 & 0.929 & 2.2 \\
\hline$\lambda E$ & 32 & 14.9 & -1.1 & 1.5 & 1.2 & 0.949 & 0.898 & 8.3 \\
\hline$H$ & 32 & 1.1 & 1.0 & 1.4 & 1.3 & 0.921 & 0.837 & 119.1 \\
\hline G & 31 & 2.1 & -0.2 & 1.0 & 0.8 & 0.017 & -0.601 & 37.7 \\
\hline All & 127 & 9.1 & -0.1 & 1.2 & 0.9 & 0.982 & 0.979 & 10.2 \\
\hline \multicolumn{9}{|l|}{ LYNE } \\
\hline$R N$ & 49 & 18.6 & -0.1 & 0.4 & 0.2 & 0.988 & 0.986 & 1.3 \\
\hline$\lambda E$ & 41 & 17.2 & 0.6 & 1.8 & 1.4 & 0.937 & 0.917 & 8.4 \\
\hline$H$ & 42 & 0.4 & -1.3 & 2.1 & 1.8 & 0.932 & 0.824 & 397.5 \\
\hline$G$ & 44 & 1.2 & 0.6 & 0.7 & 0.6 & 0.618 & -0.400 & 48.8 \\
\hline All & 176 & 9.6 & -0.1 & 1.4 & 1.0 & 0.978 & 0.978 & 10.1 \\
\hline \multicolumn{9}{|l|}{ LYSE } \\
\hline$R N$ & 44 & 17.6 & 0.0 & 0.7 & 0.4 & 0.950 & 0.949 & 2.5 \\
\hline$\lambda E$ & 36 & 15.4 & -0.1 & 1.6 & 1.2 & 0.936 & 0.923 & 8.1 \\
\hline$H$ & 37 & 1.0 & -0.2 & 1.4 & 1.1 & 0.878 & 0.874 & 111.4 \\
\hline G & 40 & 1.5 & 0.3 & 0.6 & 0.4 & 0.392 & 0.189 & 30.6 \\
\hline All & 157 & 9.1 & 0.0 & 1.1 & 0.8 & 0.983 & 0.982 & 8.7 \\
\hline
\end{tabular}

${ }^{\text {a }}$ Here $N$ is the number of observations, $\bar{O}$ is the mean observed flux, RMSD is the root-mean-square difference between the modeled $(P)$ and observed $(O)$ quantities, MBE is

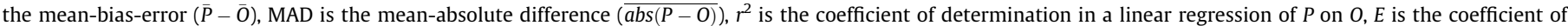
efficiency [66], and the percent error is defined as the mean-absolute-difference between $P$ and $O$ divided by the mean observed flux. 
Center for Atmospheric Research Mesoscale Model (MM5) [61]. MM5 was run at half-hourly timesteps over the continental US at a spatial resolution of $36 \mathrm{~km}$. Initial and boundary conditions for the MM5 runs were obtained from the National Centers for Environmental Prediction FNL (Final) Analysis.

\section{Results}

\subsection{Local application of the TSEB}

To evaluate the performance of the two-source land-surface representation used in ALEXI/DisALEXI under the advective conditions that prevailed during BEAREX08, the TSEB was first evaluated using "optimal inputs" collected locally at two EC (F1NE and F2SE) and two lysimeter (LYNE and LYSE) sites in the eastern irrigated cotton field. In these tests, LST was obtained by inverting upwelling longwave radiation measurements from the CNR1 4-component net radiometers deployed at each site, using the Stephan-Boltzmann law. This tends to give a more representative value of the LST over the EC measurement footprint than can be provided with narrower beam infrared thermometers [62]. Daily time series of LAI and vegetation height developed using in situ observations and aircraft NDVI [48] were used to describe canopy evolution over the modeling period in these tests.

Scatter plots of daily TSEB modeled vs. observed fluxes are shown in Fig. 4, with statistics provided in Table 2. Mean absolute difference (MAD) errors in $\lambda E$ are $1.2-1.4 \mathrm{MJ} \mathrm{m}^{-2} \mathrm{~d}^{-1}$, or $8-9 \%$ of the mean observed flux. This good agreement suggests that the modified Priestley-Taylor transpiration sub-model in the TSEB performs well in estimating daily total latent heat flux throughout most of the experiment. During the highly advective periods around DOY 216-217, TSEB underestimates $\lambda E$ by approximately $10 \%$ at F1NE, LYNE, and LYSE, but provides good estimates at F2SE. Average $\lambda E$ over the experiment is modeled by the TSEB to within errors of $0.5-7 \%$ at all sites, indicating reasonable retrieval of fluxes at seasonal timescales using the fundamental land-surface representation in ALEXI/DisALEXI. Note that while MAD errors for $H$ and $G$ are comparable or smaller than those for $\lambda E$, the percent errors are relatively large because the magnitude of the observed flux is small, and can be negative during the course of the day.

\subsection{DisALEXI on Landsat imaging dates}

TSEB flux retrievals using remote input information, as implemented in DisALEXI, were also compared with observations. Radiation and energy fluxes were evaluated at instantaneous, hourly, and daily timesteps, combining all available data from the 9 flux
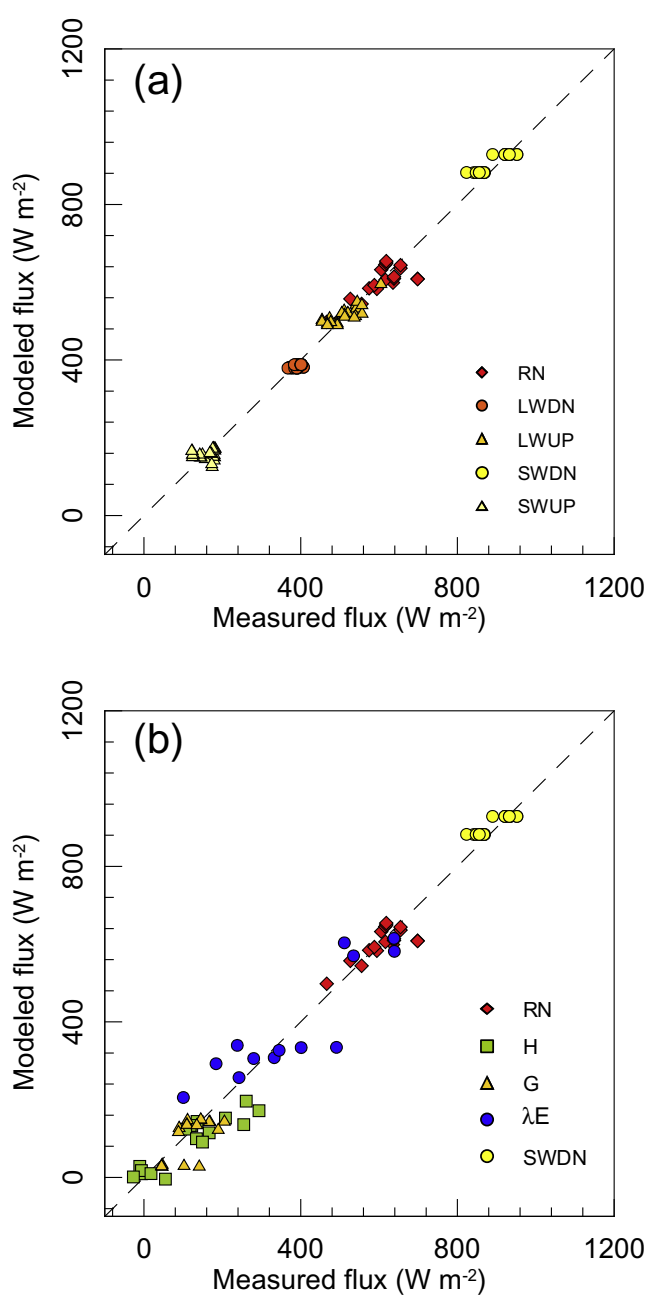

Fig. 5. Fluxes measured at 9 flux sites at the time of the Landsat overpasses compared to modeled instantaneous fluxes of: (a) net radiation (RN) components including shortwave downwelling and upwelling (SWDN and SWUP) and longwave downwelling and upwelling (LWDN and LWUP) radiation, and (b) energy budget components.

sites listed in Table 1, and for the 2 Landsat dates (DOY 187 and 219) during the flux data collection period.

Fig. 5a shows instantaneous net radiation components at the time of Landsat overpass, generated with the analytical canopy radiative transfer model using TSEB estimates of $T_{C}$ and $T_{S}$. The model-computed system albedos reproduce measurements of reflected shortwave radiation, while $T_{C}$ and $T_{S}$ yield reasonable values of upwelling longwave emission. Instantaneous system (soil + canopy) flux components produced by TSEB are compared with

Table 3

Quantitative measures of DisALEXI model performance ${ }^{\mathrm{a}}$ on Landsat imaging days for all flux sites combined (instantaneous fluxes at overpass time).

\begin{tabular}{|c|c|c|c|c|c|c|c|c|}
\hline Flux & $\mathrm{N}$ & $\overline{\mathrm{O}}\left(\mathrm{W} \mathrm{m}^{-2}\right)$ & $\operatorname{MBE}\left(\mathrm{W} \mathrm{m}^{-2}\right)$ & $\operatorname{RMSD}\left(\mathrm{W} \mathrm{m}^{-2}\right)$ & $\operatorname{MAD}\left(\mathrm{W} \mathrm{m}^{-2}\right)$ & $r^{2}\left(\mathrm{~W} \mathrm{~m}^{-2}\right)$ & $E\left(\mathrm{~W} \mathrm{~m}^{-2}\right)$ & \% Error \\
\hline \multicolumn{9}{|c|}{ Energy budget } \\
\hline RN & 18 & 611.0 & -7.4 & 37.7 & 29.5 & 0.550 & 0.532 & 4.8 \\
\hline$\lambda E$ & 13 & 379.9 & 10.4 & 77.2 & 63.8 & 0.789 & 0.783 & 16.8 \\
\hline $\mathrm{H}$ & 17 & 115.9 & -24.2 & 54.7 & 43.0 & 0.810 & 0.691 & 37.1 \\
\hline G & 18 & 116.0 & -10.7 & 42.0 & 32.3 & 0.452 & 0.258 & 27.9 \\
\hline All & 66 & 303.0 & -9.1 & 53.1 & 40.5 & 0.951 & 0.949 & 13.4 \\
\hline \multicolumn{9}{|c|}{ Net radiation components } \\
\hline LWDN & 18 & 391.2 & -6.4 & 11.8 & 9.6 & 0.176 & -0.185 & 2.5 \\
\hline LWUP & 18 & 510.7 & 15.9 & 23.8 & 18.4 & 0.893 & 0.631 & 3.6 \\
\hline SWDN & 18 & 891.6 & 13.6 & 25.2 & 20.5 & 0.843 & 0.611 & 2.3 \\
\hline SWUP & 18 & 161.1 & -1.4 & 27.4 & 23.6 & 0.000 & -6.005 & 14.6 \\
\hline
\end{tabular}

\footnotetext{
${ }^{\text {a }} N, \bar{O}, R M S D, M B E, r^{2}, E$, and \% error are defined as in Table 2 .
} 


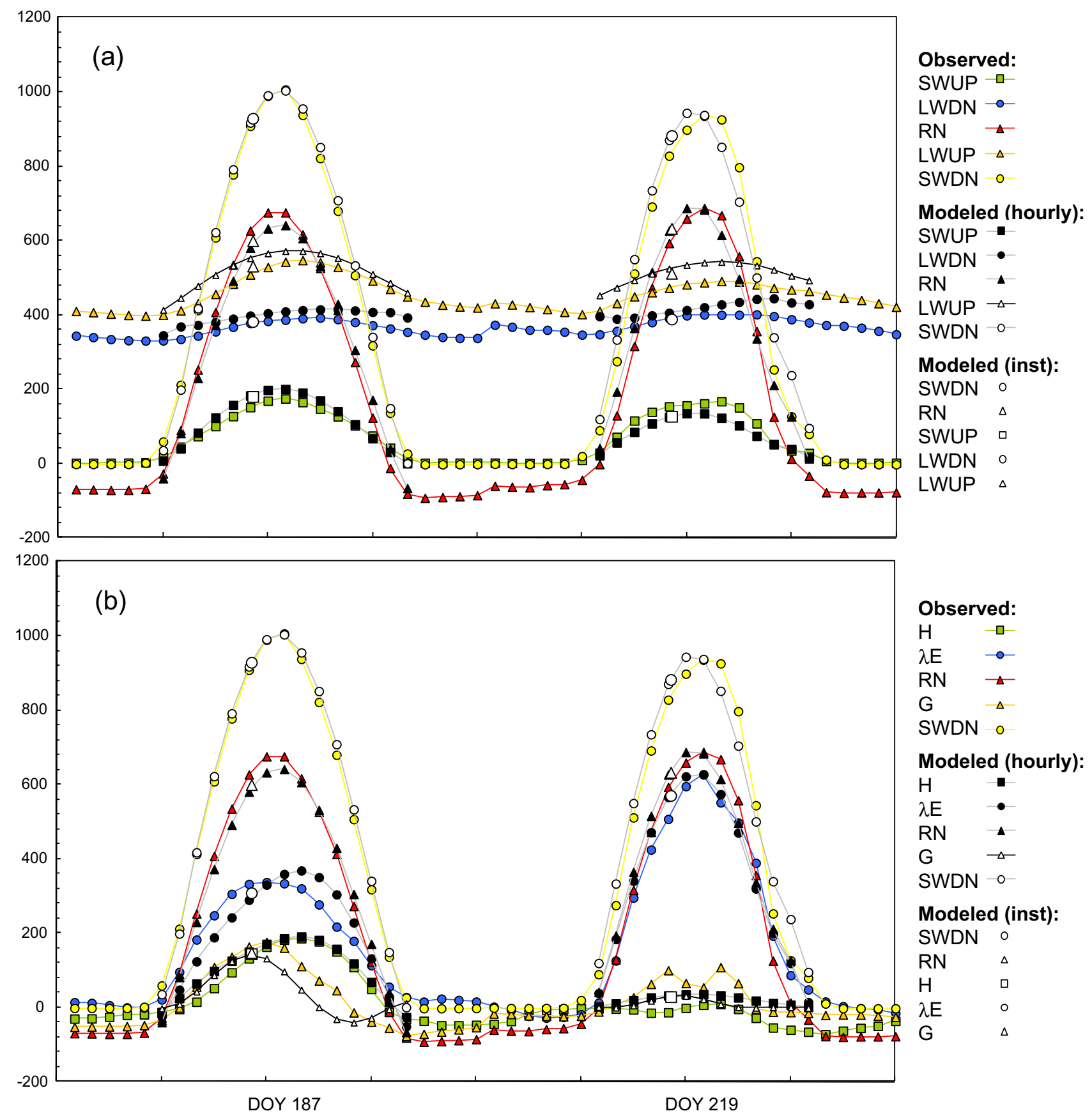

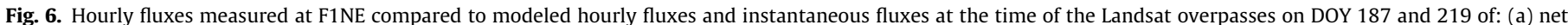
radiation components, and (b) energy budget components.

observations in Fig. 5b, with statistics in Table 3. MAD errors in $\lambda E$ at the time of the Landsat overpass are $17 \%$ for all sites combined, with small bias (3\%).

As an example of hourly flux retrieval accuracy, Fig. 6a compares hourly time series of net radiation components measured at F1NE on each Landsat day with model estimates, using the temperature increment formulation described in Section 2.4 to estimate upwelling longwave radiation. A scatterplot showing hourly data from all sites is shown in Fig. 7a. This formulation appears to work well for radiation component estimation for these clear Landsat days, where $T_{C}$ and $T_{S}$ can be retrieved from the satellite LST inputs. Hourly time series of modeled and measured energy balance fluxes at F1NE are also shown in Fig. 6b, with scatterplots for all sites in Fig. 7b, demonstrating reasonable fidelity in energy budget partitioning over a range in vegetation and micrometeorological conditions. Hourly $\lambda E$ fluxes for Landsat days and sites are reproduced with average errors of $23 \%$, and minimal bias (Table 4 ). Hourly sensible heat flux is underestimated at the high end, primarily at the rainfed sites. The formulation connecting hourly soil heat flux to net radiation at the soil surface, proposed by Santanello and Friedl [45], performs well in describing the diurnal variation in $G_{i}$ as shown in Fig. 6b. In comparison, the fixed fraction ( $G=0.3$ $R N_{S}$ ) method used in the original TSEB framework [19] tends to overestimate $G_{i}$ in the afternoon, although it is reasonable midday near the time of the Landsat overpass.

Finally, the hourly fluxes were aggregated into daytime totals and compared with measured fluxes on the Landsat imaging dates in Fig. 8, with associated statistics in Table 5. Errors at the daily 

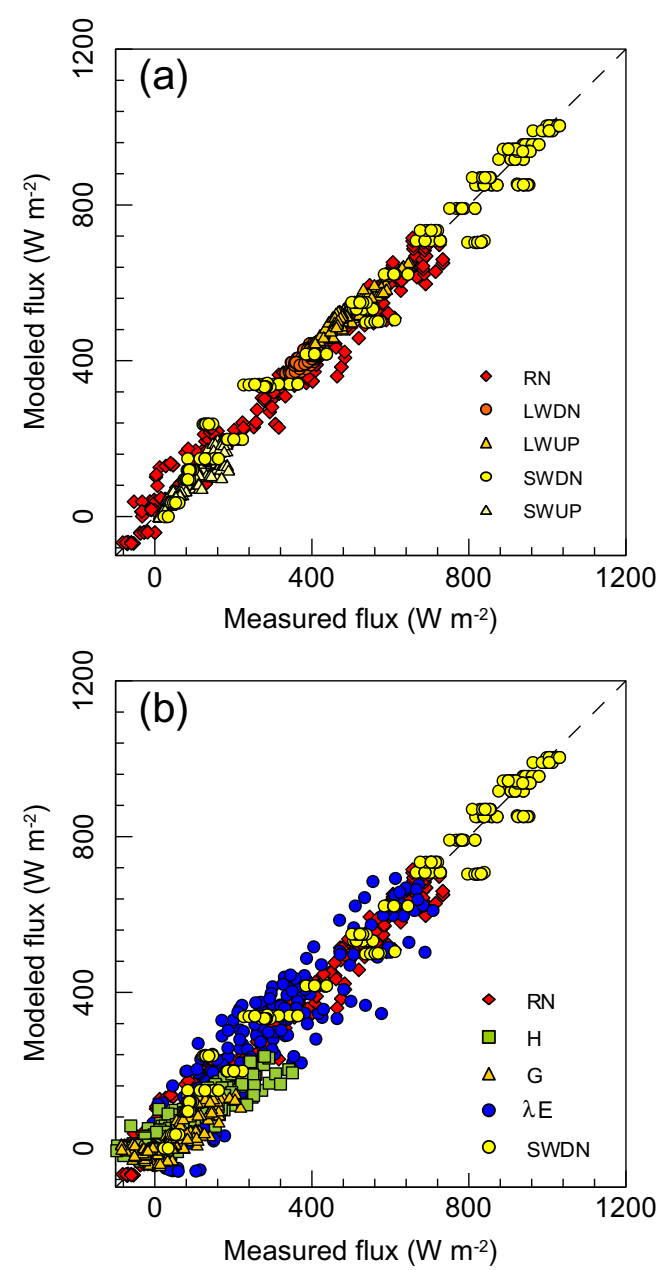

Fig. 7. Hourly fluxes measured at 9 flux sites on Landsat imaging days 187 and 219 compared to modeled hourly fluxes of: (a) net radiation components, and (b) energy budget components.

timestep are smaller than for hourly fluxes due to cancellation of random errors through the course of the day. MAD in daytime $\lambda E$ is $1.4 \mathrm{MJ} \mathrm{m}^{-2} \mathrm{~d}^{-1}(11 \%)$ for the Landsat retrievals, compared to errors of $1.2-1.4 \mathrm{MJ} \mathrm{m}^{-2} \mathrm{~d}^{-1}(9 \%)$ when the TSEB was applied to in situ inputs, suggesting accuracy was not greatly impacted by using remote input data. Errors in Landsat-derived $\lambda E$ are smaller when the irrigated sites are considered in isolation, reducing to $1.0 \mathrm{MJ} \mathrm{m}^{-2} \mathrm{~d}^{-1}$ (7\%). These errors - for Landsat days when fluxes can be modeled directly - serve as the baseline against which to assess the accuracy of the daily interpolated fluxes, presented below.
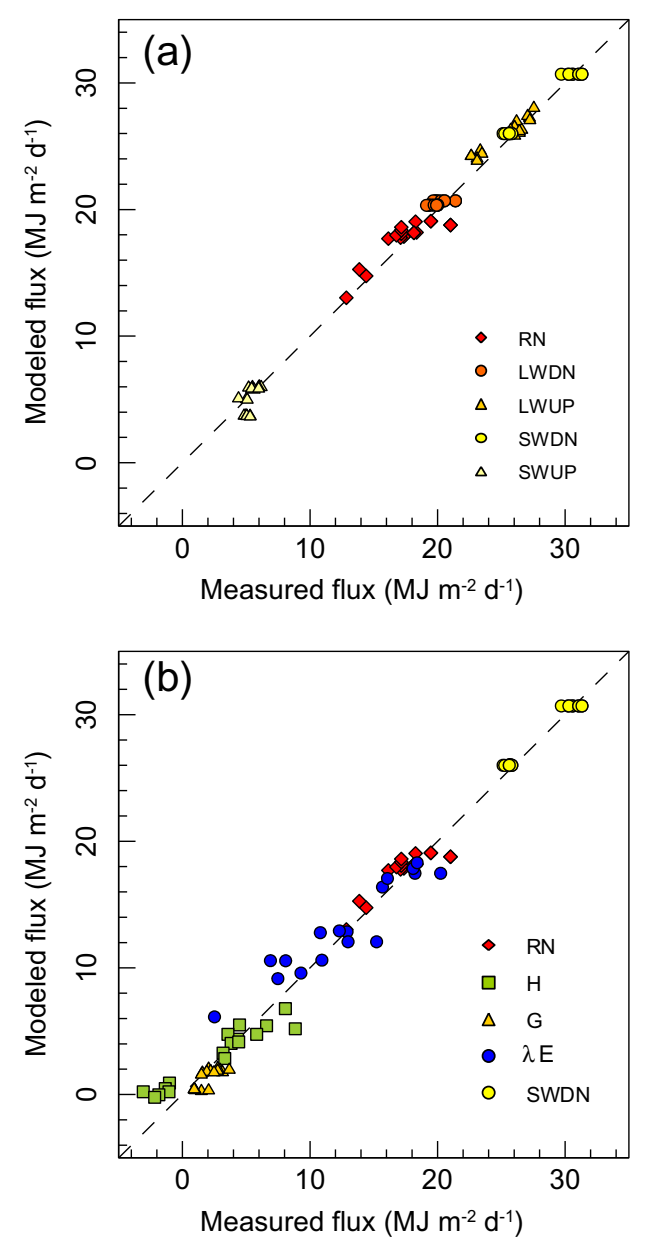

Fig. 8. Daytime integrated fluxes measured at 9 flux sites on Landsat imaging days 187 and 219 compared to modeled daytime fluxes of: (a) net radiation components, and (b) energy budget components for two Landsat dates.

\subsection{Landsat ET interpolation}

Fig. 9 compares time traces of the two reference ET (RET) datastreams used in the daily interpolation at tower site F1NE, derived with local and remote inputs. The two datastreams agree moderately well, with a MAD of $2 \mathrm{MJ} \mathrm{m}^{-2} \mathrm{~d}^{-1}(\sim 10 \%$ of the mean locally derived RET). The RET data form an upper envelope for daily EC fluxes for F1NE on most days, with the actual and reference fluxes converging as the canopy begins to close, suggesting that these values are indeed generally representative of the maximum potential ET on any given day.

Table 4

Quantitative measures of DisALEXI model performance ${ }^{\mathrm{a}}$ on Landsat imaging days for all flux sites combined (hourly fluxes).

\begin{tabular}{|c|c|c|c|c|c|c|c|c|}
\hline Flux & $N$ & $\bar{O}\left(\mathrm{~W} \mathrm{~m}^{-2}\right)$ & $\operatorname{MBE}\left(\mathrm{W} \mathrm{m}^{-2}\right)$ & $\operatorname{RMSD}\left(\mathrm{W} \mathrm{m}^{-2}\right)$ & $\operatorname{MAD}\left(\mathrm{W} \mathrm{m}^{-2}\right)$ & $r^{2}$ & $E$ & \% Error \\
\hline \multicolumn{9}{|c|}{ Energy budget } \\
\hline RN & 252 & 347.1 & 1.8 & 43.9 & 33.5 & 0.975 & 0.971 & 9.7 \\
\hline$\lambda E$ & 237 & 253.2 & 7.5 & 72.7 & 58.6 & 0.861 & 0.848 & 23.2 \\
\hline $\mathrm{H}$ & 237 & 54.7 & 6.3 & 56.0 & 39.5 & 0.807 & 0.726 & 72.1 \\
\hline G & 252 & 40.6 & -11.4 & 42.6 & 32.8 & 0.617 & 0.586 & 80.8 \\
\hline All & 978 & 174.5 & 0.9 & 54.8 & 40.9 & 0.936 & 0.936 & 23.4 \\
\hline \multicolumn{9}{|c|}{ Net radiation components } \\
\hline LWDN & 252 & 384.5 & 20.5 & 24.6 & 21.5 & 0.648 & -0.352 & 5.6 \\
\hline LWUP & 252 & 488.9 & 26.6 & 31.9 & 27.3 & 0.889 & 0.623 & 5.6 \\
\hline SWDN & 252 & 557.1 & 4.4 & 46.3 & 34.2 & 0.982 & 0.981 & 6.1 \\
\hline SWUP & 252 & 105.7 & -3.5 & 22.5 & 16.8 & 0.867 & 0.848 & 15.9 \\
\hline
\end{tabular}

\footnotetext{
${ }^{\text {a }} N, \bar{O}, R M S D, M B E, r^{2}, E$, and \% error are defined as in Table 2.
} 
Table 5

Quantitative measures of DisALEXI model performance ${ }^{a}$ on Landsat imaging days for all flux sites combined (daytime integrated fluxes).

\begin{tabular}{|c|c|c|c|c|c|c|c|c|}
\hline Flux & $N$ & $\bar{O}\left(\mathrm{MJ} \mathrm{m}^{-2} \mathrm{~d}^{-1}\right)$ & $\operatorname{MBE}\left(\mathrm{MJ} \mathrm{m}^{-2} \mathrm{~d}^{-1}\right)$ & $\operatorname{RMSD}\left(\mathrm{MJ} \mathrm{m}^{-2} \mathrm{~d}^{-1}\right)$ & $\operatorname{MAD}\left(\mathrm{MJ} \mathrm{m}^{-2} \mathrm{~d}^{-1}\right)$ & $r^{2}$ & E & $\%$ Error \\
\hline \multicolumn{9}{|c|}{ Energy budget } \\
\hline RN & 18 & 17.4 & 0.3 & 1.1 & 0.9 & 0.760 & 0.731 & 5.0 \\
\hline$\lambda E$ & 17 & 12.7 & 0.5 & 1.9 & 1.4 & 0.888 & 0.841 & 11.3 \\
\hline $\mathrm{H}$ & 17 & 2.7 & 0.4 & 1.7 & 1.3 & 0.914 & 0.792 & 49.0 \\
\hline G & 18 & 2.0 & -0.6 & 0.8 & 0.6 & 0.558 & 0.061 & 30.7 \\
\hline All & 70 & 8.8 & 0.1 & 1.4 & 1.1 & 0.963 & 0.963 & 12.0 \\
\hline \multicolumn{9}{|c|}{ Net radiation components } \\
\hline LWDN & 18 & 20.0 & 0.5 & 0.7 & 0.7 & 0.374 & -0.384 & 3.3 \\
\hline LWUP & 18 & 25.4 & 0.6 & 0.9 & 0.7 & 0.923 & 0.741 & 2.7 \\
\hline SWDN & 18 & 28.1 & 0.2 & 0.5 & 0.4 & 0.976 & 0.963 & 1.5 \\
\hline SWUP & 18 & 5.4 & -0.2 & 0.8 & 0.7 & 0.365 & -2.248 & 12.2 \\
\hline
\end{tabular}

${ }^{\text {a }} N, \bar{O}, R M S D, M B E, r^{2}, E$, and \% error are defined as in Table 2.

Daily observed and interpolated fluxes (using both local and remote RET) are displayed in Fig. 10 for each of the 9 flux sites. The interpolation does not completely reproduce peaks in ET following irrigation/rainfall events that occur between Landsat overpasses. In this case, the Landsat 5 overpass timings generally coincided with local minima between irrigation-induced ET pulses, tending to negatively bias daily interpolated fluxes (Table 6). Given this timing sequence, underestimation of cumulative fluxes would occur even if the instantaneous Landsat retrievals were perfect. However, the interpolation does capture the advective enhancement in ET from the irrigated sites occurring around DOY 217. This information is conveyed to the interpolation algorithm by the daily PMbased reference ET data.

The remote and local RET time series used in the interpolation yield MAD in EDAY of 3.0-3.3 $\mathrm{MJ} \mathrm{m}^{-2} \mathrm{~d}^{-1}$ (23-26\%), respectively, at daily timesteps for all sites combined; roughly double the errors on the Landsat days alone. The mean bias error (MBE) for the interpolated time series using remote reference ET ranged between near-zero to $20 \%$ of the mean observed daily flux. This is a measure of the accuracy with which seasonal cumulative ET is reproduced. In this case, there was no advantage to using local measurements of reference ET to drive the interpolation - the remote datastream performed as well if not better.

Of the irrigated sites, interpolations at sites in the SE field were more accurate than at sites in the NE field. Averaging fluxes from the three flux sites in each field yielded MAD and MBE of $2.6 \mathrm{MJ} \mathrm{m}^{-2} \mathrm{~d}^{-1}(18 \%)$ and $-0.7 \mathrm{MJ} \mathrm{m}^{-2} \mathrm{~d}^{-2}$ (5\%), respectively, in the SE field, with values of $3.5 \mathrm{MJ} \mathrm{m}^{-2} \mathrm{~d}^{-1}(23 \%)$ and $-2.3 \mathrm{MJ} \mathrm{m}^{-2} \mathrm{~d}^{-1}$ (14\%) for the NE field. Alfieri et al. [48] analyzed high-resolution maps of LAI derived from airborne NDVI imagery and ground observations collected during the experiment and determined that the NE field was significantly patchier in vegetation cover than was the SE field during BEAREX08. In particular, the LAI at LYNE differed from the field average by up to 1.5 , which would lead to unrepresentatively high transpiration rates over the NE lysimeter. Evett et al. (2012) showed that NE lysimeter ET

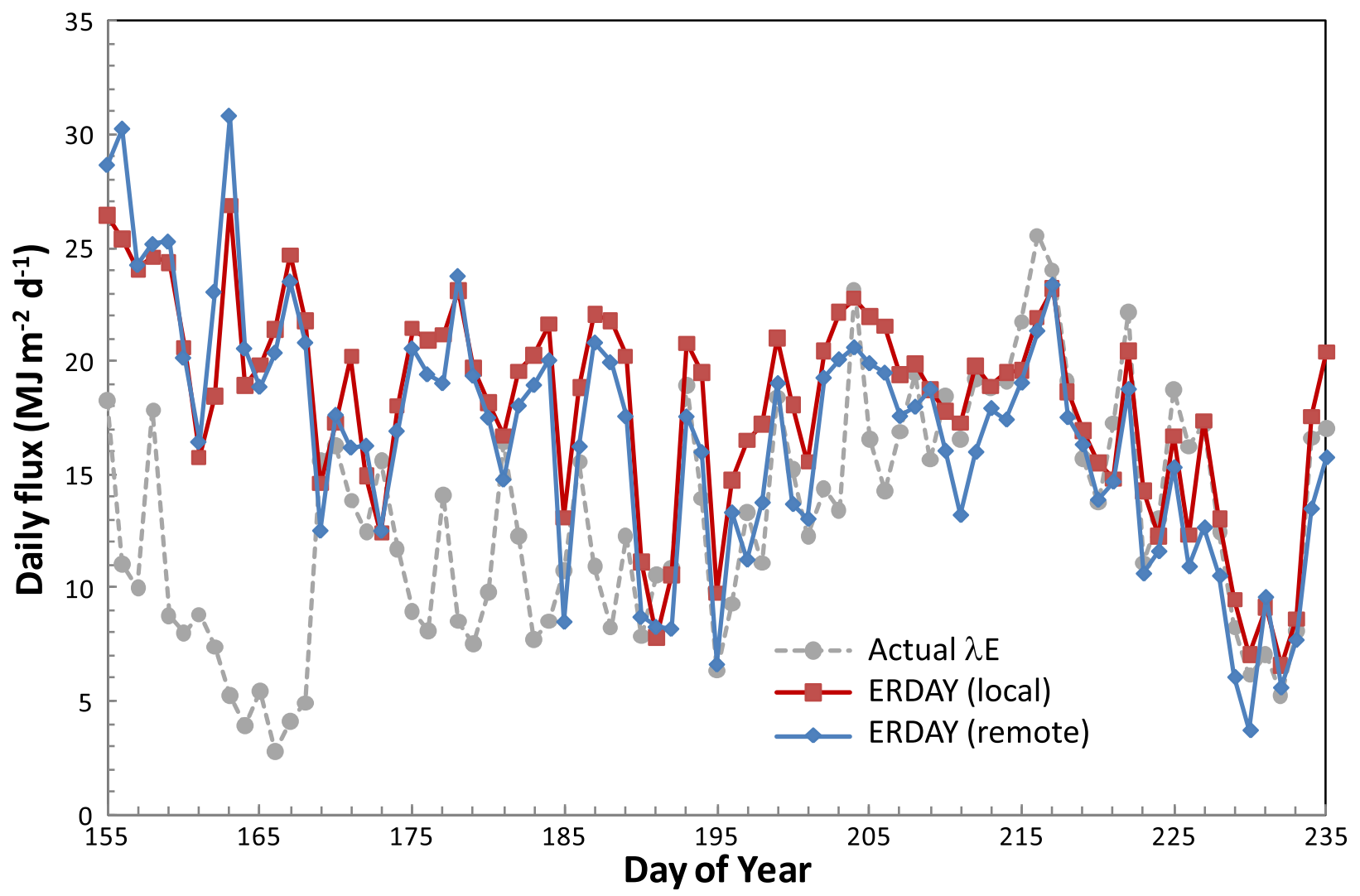

Fig. 9. Daily latent heat flux observed at F1NE compared with daily RET computed using local and remote inputs. 


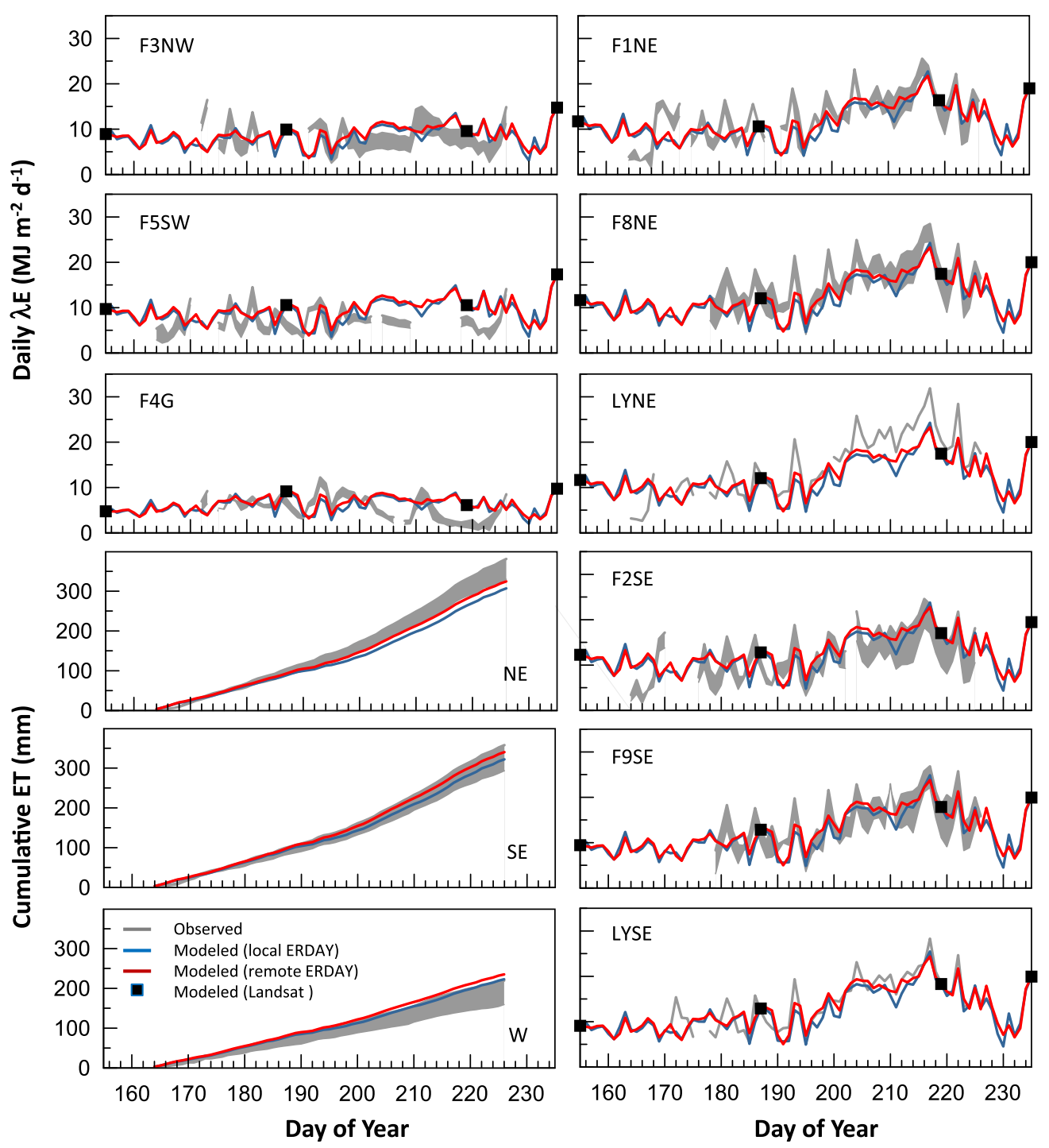

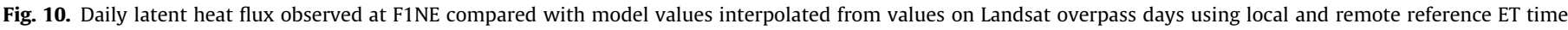

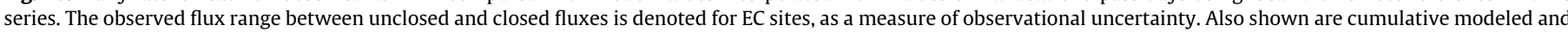
measured ET averaged over the NE, SE and W fields.

was greater than that in the NE field during the period of rapid LAI increase, while SE lysimeter ET matched SE field ET well throughout the season. This may contribute the discrepancies at LYNE and the collocated F8NE EC tower in Fig. 10, where the 30-m DisALEXI fluxes tend to underestimate peak observed ET. In contrast, fluxes at LYSE and SE EC towers are well-reproduced by DisALEXI.

While no single flux site had a complete time-series of observations required to compute cumulative fluxes, average seasonal flux accumulations are also shown in Fig. 10 for flux sites in the NE, SE, and $\mathrm{W}$ fields. In each case, the cumulative model flux using remote RET is bracketed or nearly bracketed by the unclosed and closed flux observations, which represents a measure of observational uncertainty in EC systems. The model reproduces cumulative closed fluxes to within $15 \%$ and $5 \%$ within the NE and SE irrigated fields, and within $10 \%$ and $7 \%$ for the $\mathrm{E}$ and $\mathrm{W}$ fields as a whole, respectively. Given the patchy nature of the NE field at the subLandsat pixel scale, a reasonable estimate of field-scale seasonal ET retrieval accuracy at CPRL is $5-10 \%$. However, retrieval accuracy from year to year at this site will depend in part on Landsat image availability and timing of acquisitions with respect to the irrigation cycle.

\subsection{Landsat-scale ET image time-series}

A time-series of latent heat flux maps over the BEAREX08 experiment site, at 5 day intervals, is shown in Fig. 11. Again, spatial $f_{R E T}$ information was updated on L5 imaging days $155,187,219$ and 235, dispersed throughout the time series. These 4 Landsat images capture important changes in irrigation management during the growing season. Irrigation shifted to the southern halves of the two large center pivot (circular) fields in the NW corner of the image. The differential in water use by the irrigated and unirrigated cotton fields (just to the east of the northernmost of these two center pivots) is evident, particularly later in the season. ET enhancements are detected associated with manure lagoons in a CAFO due south of the southernmost of these pivots, and with lawns in the residential section of Bushland along the eastern border of the image. Linear irrigation was commenced in a large field along the SE border of the image midway through this time period.

This detailed level of interpretation of land- and water-management practices is not generally possible with MODIS-scale imagery (1-km TIR resolution). The Landsat scale is critical for associating satellite-derived signals with human activity on the ground. 
Table 6

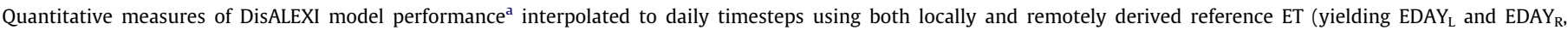
respectively).

\begin{tabular}{|c|c|c|c|c|c|c|c|c|c|}
\hline Flux & $\mathrm{N}$ & $\bar{O}\left(\mathrm{MJ} \mathrm{m}^{-2} \mathrm{~d}^{-1}\right)$ & $\operatorname{MBE}\left(\mathrm{MJ} \mathrm{m}^{-2} \mathrm{~d}^{-1}\right)$ & 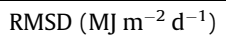 & $\operatorname{MAD}\left(\mathrm{MJ} \mathrm{m}^{-2} \mathrm{~d}^{-1}\right)$ & $r^{2}$ & $E$ & \% Error & Avg\% Error \\
\hline \multicolumn{10}{|l|}{ F1NE } \\
\hline $\mathrm{EDAY}_{\mathrm{L}}$ & 60 & 13.8 & -2.3 & 4.5 & 3.7 & 0.455 & 0.243 & 26.8 & 16.6 \\
\hline $\mathrm{EDAY}_{\mathrm{R}}$ & 60 & 13.8 & -1.6 & 4.1 & 3.3 & 0.480 & 0.373 & 24.1 & 11.9 \\
\hline \multicolumn{10}{|l|}{ F2SE } \\
\hline $\mathrm{EDAY}_{\mathrm{L}}$ & 56 & 13.4 & -0.8 & 4.1 & 3.4 & 0.432 & 0.390 & 25.0 & 5.7 \\
\hline $\mathrm{EDAY}_{\mathrm{R}}$ & 56 & 13.4 & 0.0 & 3.8 & 3.1 & 0.480 & 0.476 & 23.0 & 0.0 \\
\hline \multicolumn{10}{|l|}{ F3NW } \\
\hline $\mathrm{EDAY}_{\mathrm{L}}$ & 46 & 9.9 & -1.2 & 3.8 & 2.8 & 0.012 & -1.092 & 28.0 & 12.2 \\
\hline $\mathrm{EDAY}_{\mathrm{R}}$ & 46 & 9.9 & -0.8 & 3.5 & 2.6 & 0.006 & -0.814 & 26.2 & 7.7 \\
\hline \multicolumn{10}{|l|}{ F4G } \\
\hline $\mathrm{EDAY}_{\mathrm{L}}$ & 53 & 6.0 & 0.5 & 3.2 & 2.8 & 0.034 & -0.628 & 46.8 & 8.0 \\
\hline $\mathrm{EDAY}_{\mathrm{R}}$ & 53 & 6.0 & 0.8 & 3.1 & 2.6 & 0.002 & -0.474 & 44.0 & 13.8 \\
\hline \multicolumn{10}{|l|}{ F5SW } \\
\hline $\mathrm{EDAY}_{\mathrm{L}}$ & 50 & 7.7 & 1.1 & 3.6 & 3.1 & 0.012 & -1.278 & 40.3 & 14.3 \\
\hline $\mathrm{EDAY}_{\mathrm{R}}$ & 50 & 7.7 & 1.6 & 3.6 & 3.2 & 0.006 & -1.270 & 41.0 & 20.8 \\
\hline \multicolumn{10}{|l|}{ F8NE } \\
\hline $\mathrm{EDAY}_{\mathrm{L}}$ & 49 & 17.3 & -4.1 & 4.8 & 4.1 & 0.735 & -0.013 & 23.7 & 23.7 \\
\hline $\mathrm{EDAY}_{\mathrm{R}}$ & 49 & 17.3 & -3.3 & 4.1 & 3.4 & 0.751 & 0.264 & 19.7 & 19.2 \\
\hline \multicolumn{10}{|l|}{ F9SE } \\
\hline $\mathrm{EDAY}_{\mathrm{L}}$ & 48 & 16.3 & -2.6 & 3.8 & 3.2 & 0.699 & 0.412 & 19.4 & 16.1 \\
\hline EDAY $_{R}$ & 48 & 16.3 & -1.8 & 3.2 & 2.6 & 0.709 & 0.578 & 16.0 & 11.1 \\
\hline \multicolumn{10}{|l|}{ LYNE } \\
\hline $\mathrm{EDAY}_{\mathrm{L}}$ & 57 & 15.2 & -2.7 & 4.7 & 4.1 & 0.741 & 0.544 & 26.9 & 17.6 \\
\hline $\operatorname{EDAY}_{\mathrm{R}}$ & 57 & 15.2 & -2.0 & 4.3 & 3.6 & 0.767 & 0.621 & 23.9 & 13.1 \\
\hline \multicolumn{10}{|l|}{ LYSE } \\
\hline $\mathrm{EDAY}_{\mathrm{L}}$ & 53 & 14.6 & -1.3 & 3.0 & 2.4 & 0.746 & 0.684 & 16.5 & 9.1 \\
\hline $\operatorname{EDAY}_{\mathrm{R}}$ & 53 & 14.6 & -0.6 & 2.8 & 2.1 & 0.750 & 0.739 & 14.4 & 3.9 \\
\hline \multicolumn{10}{|l|}{ All } \\
\hline $\mathrm{EDAY}_{\mathrm{L}}$ & 472 & 12.7 & -1.5 & 4.0 & 3.3 & 0.615 & 0.553 & 25.9 & 11.7 \\
\hline $\mathrm{EDAY}_{\mathrm{R}}$ & 472 & 12.7 & -0.9 & 3.7 & 3.0 & 0.652 & 0.628 & 23.3 & 6.7 \\
\hline
\end{tabular}

a $N, \bar{O}, R M S D, M B E, r^{2}, E$, and \% error are defined as in Table 2 , and avg \% error is given by $100 \times$ abs $(\mathrm{MBE}) / \overline{\mathrm{O}}$.

However, MODIS-like instruments can provide useful and temporally dense information about water use at coarser scales, reflecting cycles in the natural water budget associated with rainfall patterns. Future work will be focused on fusing ET datasets from multiple sensors to optimize spatial and temporal sampling over a broader range in scales [63].

\subsection{Discussion and conclusions}

This study explores errors in flux estimates retrieved using the TIR-based ALEXI/DisALEXI modeling system at various timescales: at instantaneous, hourly and daily timesteps on Landsat imaging dates, and upscaled to seasonal cumulative values using a simple interpolation procedure requiring only remotely obtained daily datastreams. The TSEB land-surface representation in ALEXI/DisALEXI reasonably reproduced observed ET fluxes even on highly advective days, despite the use of the modified PT approach (which neglects advective effects) to parameterize canopy transpiration fluxes. This is consistent with results of Colaizzi et al. [26], who compared PM and PT configurations for describing the canopy transpiration component of the total ET within the TSEB with observations from BEAREX08. They found that the two approaches yielded similar system (soil + canopy) evaporative fluxes during the day, while the PM form yielded more realistic partitioning between soil evaporation and canopy transpiration, and better nighttime flux estimates. In effect, underestimates of canopy transpiration due to neglect of advection by the PT approach are balanced by an overestimation of soil evaporation, yielding a relatively unbiased estimate of total ET. The PM approach of Colaizzi et al. [26] will be tested in future studies, to extend analyses from daytime only to full day + night flux time sequences.
Other general findings reflect the performance of parameterizations used to extrapolate instantaneous fluxes at the Landsat overpass time to hourly values. In particular, a formulation for the upwelling longwave component of net radiation using TSEB-derived soil and canopy temperature increments tied to the hourly air temperature inputs was tested and provided excellent agreement with diurnal observations collected with 4-component net radiometers. In addition, the soil heat flux parameterization suggested by Santanello and Friedl [45] reproduced the diurnal curve reflected in the observations, and will be adopted in future studies with ALEXI/DisALEXI.

In upscaling to daily timesteps, gap-filling periods between Landsat overpasses, we found no significant value in using local RET data in comparison with datastreams that can be computed using only remote input data. This would likely not be the case if the interpolation procedure also included a running soil moisture model used to evolve $f_{R E T}$ describing the soil evaporation component, as in the METRIC approach [18]. Such a procedure improves local seasonal ET estimates, but requires good knowledge of both rainfall and local soil texture - data that will not be readily available for general applications in sparsely instrumented areas, and may in fact exacerbate seasonal errors if sub-optimal inputs are used [64].

While the study described here provides general insights into modeling and temporal upscaling issues that can be expected with ALEXI/DisALEXI, these results are to some degree specific to this particular set of observational data. The derived accuracies and seasonal biases for irrigated flux sites are sensitive to the degree of synchronization between the Landsat imaging and site-specific irrigation cycles. In rainfed agricultural landscapes, where moisture variability is controlled by nature and will be more random 

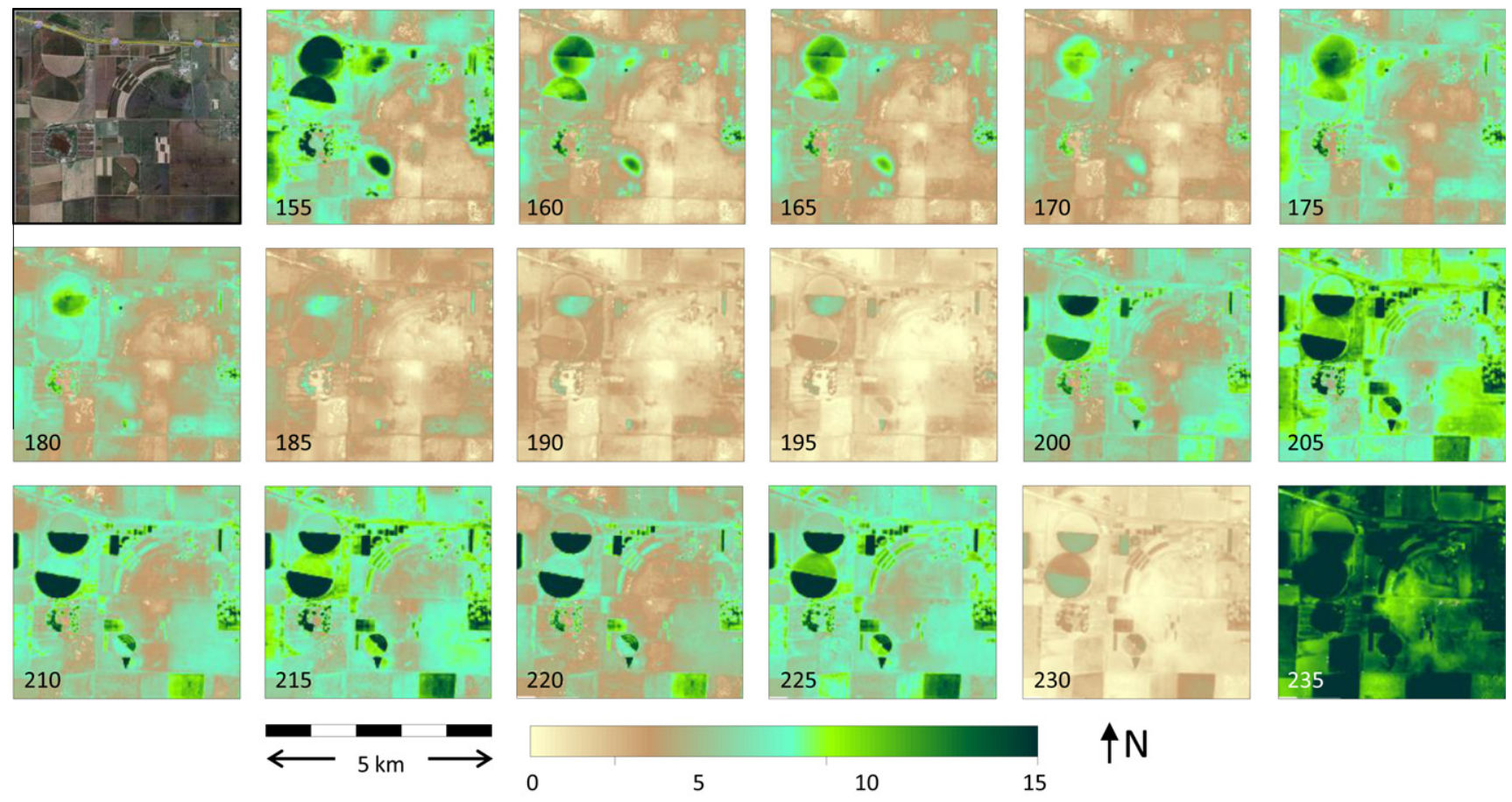

Daily $\lambda E\left(\mathrm{MJ} \mathrm{m}^{-2} \mathrm{~d}^{-1}\right)$

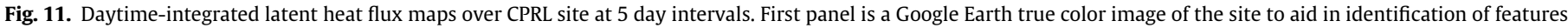
in the $\lambda E$ maps.

with respect to satellite timing, we may obtain very different results. In addition, this study represented a test of a relatively dense Landsat time-series, collected in an arid climate (relatively low cloud cover) with near-optimal imaging conditions. A more definitive description of expected modeling errors at daily and seasonal intervals will be obtained by evaluating an ensemble of flux sites, in different climatic regions and under different management strategies. Such an ensemble can also assist in better defining optimal orbital and imaging characteristics of future satellite missions dedicated to water resource monitoring.

Future modifications to the interpolation scheme will integrate daily kilometer-scale ET maps from MODIS, which may provide useful information about moisture variability at these coarser scales between Landsat overpasses, particularly over rainfed landscapes. Such information can be integrated using the MODIS-Landsat reflectance fusion algorithm described by Gao et al. [65], with preliminary applications to ET time series outlined by Anderson et al. [63]. In this case, the MODIS TIR data may provide a valuable proxy for the in situ precipitation data required by the METRIC approach, adding information about changing soil evaporation conditions between Landsat overpasses. While we cannot expect MODIS-derived ET to reproduce peaks associated with irrigation events at the scale of individual fields, it may add value at larger scales and particularly in more humid climates where clear-sky Landsat acquisitions are less frequent. In addition, microwavebased retrievals of soil moisture can provide background information under both clear and cloudy conditions, albeit at much coarser spatial resolutions.

\section{Acknowledgements}

The US Department of Agriculture (USDA) prohibits discrimination in all its programs and activities on the basis of race, color, national origin, age, disability, and where applicable, sex, marital status, familial status, parental status, religion, sexual orientation, genetic information, political beliefs, reprisal, or because all or part of an individual's income is derived from any public assistance program. (Not all prohibited bases apply to all programs.) Persons with disabilities who require alternative means for communication of program information (Braille, large print, audiotape, etc.) should contact USDA's TARGET Center at (202) 720-2600 (voice and TDD). To file a complaint of discrimination, write to USDA, Director, Office of Civil Rights, 1400 Independence Avenue, S.W., Washington, D.C. 20250-9410, or call (800) 795-3272 (voice) or (202) 720-6382 (TDD). USDA is an equal opportunity provider and employer.

\section{References}

[1] Anderson MC, RG Allen, A Morse, WP Kustas. Use of Landsat thermal imagery in monitoring evapotranspiration and managing water resources. Remote Sens Environ, 2012, in press.

[2] Allen RG, Tasumi M, Morse A, Trezza R, Wright JL, Bastiaanssen WGM, et al Satellite-based energy balance for mapping evapotranspiration with internalized calibration (METRIC) - applications. ASCE J Irrig Drainage Eng 2007; 133:395-406.

[3] Morse A, Kramber WJ, Allen RG. Preliminary computation evapotranspiration by land cover type using TM data and SEBAL. International Geoscience and Remote Sensing Symposium, Toulouse, France, 2003. p. 2956-8.

[4] Morse A, Kramber WJ, Allen RG. Mapping evapotranspiration from satellites. Southwest Hydrology. May/June 2005. p. 18-9.

[5] Kramber WJ, Morse A, Allen RG. Mapping evapotranspiration: a remote sensing innovation. Photogramm Eng Remote Sens 2010;76:6-10.

[6] Evett SR, Kustas WP, Gowda PH, Prueger JH, Howell TA Overview of the Bushland Evapotranspiration and Agricultural Remote sensing EXperiment 2008 (BEAREX08): A field experiment evaluating methods quantifying ET at multiple scales. Adv Water Resour 2012;50:4-19.

[7] McGuire VL, Stanton CP, Fischer BC. Water-level changes, 1980 to 1997, and saturated thickness, 1996-97, in the high plains aquifer (Fact Sheet FS-124-99). US Geological Survey, Washington, DC, 1999. Available on the World Wide Web: http://ne.water.usgs.gov/highplains/hp97_web_report/fs-124-99.htm.

[8] McAneney KJ, Brunet Y, Iter B, et al. Downwind evolution of transpiration by two irrigated crops under conditions of local advection. J Hydrol 1994; 161:375-88.

[9] Prueger JH, Hipps LE, Cooper DI. Evaporation and the development of the local boundary layer over an irrigated surface in an arid region. Agric Meteorol 1996;78:223-37. 
[10] Zermeno-Gonzalez A, Hipps LE. Downwind evolution of surface fluxes over a vegetated surface during local advection of heat and saturation deficit. J Hydrol 1997;192:189-210.

[11] Figuerola PI, Berliner PR. Evapotranspiration under advective conditions. Int J Biometeorol 2005;49:403-16.

[12] Kalma JD, McVicar TR, McCabe MF. Estimating land surface evaporation: a review of methods using remotely sensing surface temperature data. Survey Geophys, 2008. DOI 10.1007/s10712-008-9037-z.

[13] Hain CR, Mecikalski JR, Anderson MC. Retrieval of an available water-based soil moisture proxy from thermal infrared remote sensing. Part I: Methodology and validation. J Hydrometeorol 2009;10:665-83.

[14] Hain CR, Crow WT, Mecikalski JR, Anderson MC, Holmes T. An intercomparison of available soil moisture estimates from thermal-infrared and passive microwave remote sensing and land-surface modeling. J Geophys Res 2011;116:D15107.

[15] Tang Q, Peterson S, Cuenca RH, Hagimoto Y, Lettenmaier DP. Satellite-based near-real-time estimation of irrigated crop water consumption. J Geophys Res 2009;114:D05144, doi:10.1029/2008JD010854.

[16] Tang Q Rosenberg EA, Lettenmaier DP. Use of satellite data to assess the impacts of irrigation withdrawals on Upper Klamath Lake, Oregon. Hydrol Earth Syst Sci 2009;13:617-27.

[17] Bastiaanssen WGM, Menenti M, Feddes RA, Holtslag AAM. A remote sensing surface energy balance algorithm for land (SEBAL); 1. Formulation. J Hydrol 1998;212-213:198-212.

[18] Allen RG, Tasumi M, Trezza R. Satellite-based energy balance for mapping evapotranspiration with internalized calibration (METRIC) - model. J Irrig Drainage Eng DOI 10.1061/(ASCE)0733-9437(2007) 133:4(380) (2007).

[19] Norman JM, Kustas WP, Humes KS. A two-source approach for estimating soil and vegetation energy fluxes from observations of directional radiometric surface temperature. Agric Meteorol 1995;77:263-93.

[20] Anderson MC, Kustas WP, Norman JM. Upscaling and downscaling a regional view of the soil-plant-atmosphere continuum. Agron J 2003;95:1408-23.

[21] Kustas WP, Norman JM. Evaluation of soil and vegetation heat flux predictions using a simple two-source model with radiometric temperatures for partia canopy cover. Agric Meteorol 1999;94:13-29.

[22] Kustas WP, Norman JM. A two-source energy balance approach using directional radiometric temperature observations for sparse canopy covered surfaces. Agronomy J 2000;92:847-54

[23] Anderson MC, Norman JM, Kustas WP, Li F, Prueger JH, Mecikalski JM. Effects of vegetation clumping on two-source model estimates of surface energy fluxes from an agricultural landscape during SMACEX. J Hydrometeorol 2005;6:892909.

[24] Priestley CHB, Taylor RJ. On the assessment of surface heat flux and evaporation using large-scale parameters. Mon Weather Rev 1972;100:81-92.

[25] Agam N, Kustas WP, Anderson MC, Norman JM, Colaizzi PD, Prueger JH. A modified two-source Priestley-Taylor approach for partial canopies. Hydrometeorol 2010;11:185-98.

[26] Colaizzi PD, Kustas WP, Anderson MC, Gowda PH, O'Shaughnessy SA, Howell $\mathrm{TA}$, et al. Two-source model estimates of evapotranspiration using component and composite surface temperatures. Adv Water Resour 2012;50:134-51.

[27] Monteith JL. Evaporation and environment. 19th Symposium for the Society for Experimental Biology. Academic Press, Inc. NY; 1965. p. 205-24.

[28] Norman JM, Divakarla M, Goel NS. Algorithms for extracting information from remote thermal-IR observations of the earth's surface. Remote Sens Environ 1995;51:157-68.

[29] McNaughton KG, Spriggs TW. A mixed-layer model for regional evaporation. Boundary-Layer Meteorol 1986;74:262-88.

[30] Kustas WP, Diak GR, Norman JM. Time difference methods for monitoring regional scale heat fluxes with remote sensing. Land Surface Hydrology, Meteorology, and Climate: Observations and Modeling 2001;3:15-29.

[31] Anderson MC, Norman JM, Diak GR, Kustas WP, Mecikalski JR. A two-source time-integrated model for estimating surface fluxes using thermal infrared remote sensing. Remote Sens Environ 1997;60:195-216.

[32] Norman JM, Anderson MC, Kustas WP, French AN, Mecikalski JR, Torn RD, et al. Remote sensing of surface energy fluxes at $101-\mathrm{m}$ pixel resolutions. Water Resour Res 2003;39. DOI:10.1029/2002WR001775.

[33] Anderson MC, Norman JM, Mecikalski JR, Torn RD, Kustas WP, Basara JB. A multi-scale remote sensing model for disaggregating regional fluxes to micrometeorological scales. J Hydrometeor 2004;5:343-63.

[34] Cammalleri C, Anderson MC, Ciraolo G, D’Urso G, Kustas WP, La Loggia G, et al Practical applications of the remote sensing-based two-source algorithm for surface energy fluxes mapping without in-situ air temperature observations Remote Sens Environ, 2012, in press.

[35] Anderson MC, Norman JM, Mecikalski JR, Otkin JP, Kustas WP. A climatological study of evapotranspiration and moisture stress across the continental US based on thermal remote sensing: I. Model formulation. J Geophys Res 2007;112:D10117, doi:10.1029/2006JD007506.

[36] Gurney RJ, Hsu AY. Relating evaporative fraction to remotely sensed data at the FIFE site. Symposium on FIFE: First ISLSCP Field Experiment, Boston, MA, 1990. p. 112-6.

[37] Sugita M, Brutsaert W. Daily evaporation over a region from lower boundary layer profiles measured with radiosondes. Water Resour Res 1991;27:747-52.
[38] Brutsaert W, Sugita M. Application of self-preservation in the diurnal evolution of the surface energy budget to determine daily evaporation. J Geophys Res 1992;97:18377-18382.

[39] Zhang L, Lemeur R. Evaluation of daily evapotranspiration estimates from instantaneous measurements. Agric Meteorol 1995;74:139-54.

[40] Crago RD. Comparison of the evaporative fraction and the Priestley-Taylor $\alpha$ for parameterizing daytime evaporation. Water Resources Res 1996;32:1403-9.

[41] Anderson MC, Norman JM, Meyers TP, Diak GR. An analytical model for estimating canopy transpiration and carbon assimilation fluxes based on canopy light-use efficiency. Agric Meteorol 2000;101:265-89.

[42] Diak GR, Bland WL, Mecikalski JR. A note on first estimates of surface insolation from GOES-8 visible satellite data. Agric Meteorol 1996;82:219-26.

[43] Diak GR, Bland WL, Mecikalski JR, Anderson MC. Satellite-based estimates of longwave radiation for agricultural applications. Agric Meteorol 2000;103:349-55.

[44] Brutsaert W. Evaporation into the atmosphere: theory, history and applications. D. Reidel, Dordrecht, Holland; 1982.

[45] Santanello JA, Friedl MA. Diurnal variation in soil heat flux and net radiation. J Appl Meteorol 2003;42:851-62.

[46] Savitzky A, Golay MJE. Smoothing and differentiation of data by simplified least squares procedures. Anal Chem 1964;36:1627-39.

[47] Allen RG, LS Pereira, D Raes, M Smith. Crop evapotranspiration: guidelines for computing crop water requirements, United Nations FAO, Irrigation and Drainage Paper 56. Rome, Italy, 1998. p. 300.

[48] Alfieri JG, Kustas WP, Prueger J, Hipps LE, Evett SR, Basara JB, et al. On the discrepancy between eddy covariance and lysimetry-based surface flux measurements under strongly advective conditions. Adv Water Resour 2012;50:62-78.

[49] Twine TE, Kustas WP, Norman JM, Cook DR, Houser PR, Meyers TP, et al. Correcting eddy-covariance flux underestimates over a grassland. Agric Meteorol 2000;103:279-300.

[50] Wilson K, Goldstein A, Falge E, Aubinet M, Baldocchi D, Berbigier P, et al. Energy balance closure at FLUXNET sites. Agric Meteorol 2002;113:223-43.

[51] Prueger JH, Hatfield JL, Kustas WP, Hipps LE, MacPherson JI, Parkin TB. Tower and aircraft eddy covariance measurements of water vapor, energy and carbon dioxide fluxes during SMACEX. J Hydrometeor 2005;6:954-60.

[52] Alfieri JG, Kustas WP, Prueger JH, Hipps LE, Chavez JL, French AN, et al. Intercomparison of nine micrometeorological stations during the BEAREX08 field campaign. J Atmos Oceanic Tech 2011;28:1390-406.

[53] Otkin JA, Anderson MC, Mecikalski JR, Diak GR. Validation of GOES-based insolation estimates using data from the United States Climate Reference Network. J Hydromet 2005;6:460-75.

[54] French AN, Norman JM, Anderson MC. A simple and fast atmospheric correction for spaceborne remote sensing of surface temperature. Remote Sens Environ 2003;87:326-33.

[55] Li F, Jackson TJ, Kustas WP, Schmugge TJ, French AN, Cosh M, et al. Deriving land surface temperature from Landsat 5 and 7 during SMEX02/SMACEX. Remote Sens Environ 2004;92:521-34.

[56] Berk A, Bernstein LS, Anderson GP, Acharya PK, Robertson DC, Chetwynd JH, et al. MODTRAN cloud and multiple scattering upgrades with application toAVIRIS. Remote Sens Environ 1998;65:367-75.

[57] Myneni RB, Hoffman S, Knyazikhin Y, Privette JL, Glassy J, Tian Y, et al. Global products of vegetation leaf area and fraction absorbed PAR from year one of MODIS data. Remote Sens Environ 2002;83:214-31.

[58] Gao F, Anderson MC, Kustas WP, Wang Y. A simple method for retrieving Leaf Area Index from Landsat using MODIS LAI products as reference. J Appl Remote Sens, 2012, in press.

[59] Masek JG, Vermote EF, Saleous NE, Wolfe R, Hall FG, Huemmrich KF, et al. A Landsat surface reflectance dataset for North America, 1990-2000. IEEE Geosci Remote Sens Lett 2006;3:68-72.

[60] Houborg R, Anderson MC. Utility of an image-based canopy reflectance modeling tool for remote estimation of LAI and leaf chlorophyll content at regional scales. J Appl Remote Sens. 3, 033529 (2009).

[61] Dudhia J. A nonhydrostatic version of the Penn State/NCAR mesoscale model: Validation test and simulation of an Atlantic cyclone and cold front. Mon Weather Rev 1993;121:1493-513.

[62] Kustas WP, Alfieri JG, Anderson MC, Colaizzi PD, Prueger JH, Neale CMU, et al Evaluating the two-source energy balance model using local thermal and surface flux observations in a strongly advective irrigated agricultural area. Adv Water Resour 2012;50:120-33.

[63] Anderson MC, Kustas WP, Norman JM, Hain CR, Mecikalski JR, Schultz L, et al. Mapping daily evapotranspiration at field to continental scales using geostationary and polar orbiting satellite imagery. Hydrol Earth Syst Sci 2011;15:223-39.

[64] Choi M, Kustas WP, Anderson MC, Allen RG, Li F, Kjaersgaard JH. An intercomparison of three remote sensing-based surface energy balance algorithms over a corn and soybean production region (Iowa, US) during SMACEX. Agric Meteorol 2009;149:2082-97.

[65] Gao F, Masek J, Schwaller M, Hall FG. On the blending of the Landsat and MODIS surface reflectance. predicting daily Landsat surface reflectance. IEE Trans Geosci Remote Sens 2006;44:2207-18.

[66] Nash LE, Sutcliffe JV. River flow forecasting through conceptual models - Part 1: a discussion of principles. J Hydrol 1970;10:282-90. 